\title{
On the structure and dynamics of Indian monsoon depressions
}

\section{Article}

Published Version

Hunt, K. M. R., Turner, A. G., Inness, P. M., Parker, D. E. and Levine, R. C. (2016) On the structure and dynamics of Indian monsoon depressions. Monthly Weather Review, 144 (9). pp. 3391-3416. ISSN 0027-0644 doi: https://doi.org/10.1175/MWR-D-15-0138.1 Available at https://centaur.reading.ac.uk/38263/

It is advisable to refer to the publisher's version if you intend to cite from the work. See Guidance on citing.

To link to this article DOI: http://dx.doi.org/10.1175/MWR-D-15-0138.1

Publisher: American Meteorological Society

All outputs in CentAUR are protected by Intellectual Property Rights law, including copyright law. Copyright and IPR is retained by the creators or other copyright holders. Terms and conditions for use of this material are defined in the End User Agreement.

\section{www.reading.ac.uk/centaur}

\section{CentAUR}

Central Archive at the University of Reading 
Reading's research outputs online 


\title{
əon the Structure and Dynamics of Indian Monsoon Depressions
}

\author{
KIERAN M. R. HUNT \\ Department of Meteorology, University of Reading, Reading, United Kingdom \\ ANDREW G. TURNER \\ NCAS-Climate, and Department of Meteorology, University of Reading, Reading, United Kingdom \\ PETER M. INNESS \\ Department of Meteorology, University of Reading, Reading, United Kingdom \\ DAVID E. PARKER AND RichaRd C. LEVINE \\ Met Office Hadley Centre, Exeter, United Kingdom
}

(Manuscript received 1 April 2015, in final form 26 January 2016)

\begin{abstract}
ERA-Interim reanalysis data from the past 35 years have been used with a newly developed feature tracking algorithm to identify Indian monsoon depressions originating in or near the Bay of Bengal. These were then rotated, centralized, and combined to give a fully three-dimensional 106-depression composite structurea considerably larger sample than any previous detailed study on monsoon depressions and their structure. Many known features of depression structure are confirmed, particularly the existence of a maximum to the southwest of the center in rainfall and other fields and a westward axial tilt in others. Additionally, the depressions are found to have significant asymmetry owing to the presence of the Himalayas, a bimodal midtropospheric potential vorticity core, a separation into thermally cold $(\sim-1.5 \mathrm{~K})$ and neutral $(\sim 0 \mathrm{~K})$ cores near the surface with distinct properties, and the center has very large CAPE and very small CIN. Variability as a function of background state has also been explored, with land-coast-sea, diurnal, ENSO, active-break, and Indian Ocean dipole contrasts considered. Depressions are found to be markedly stronger during the active phase of the monsoon, as well as during La Niña. Depressions on land are shown to be more intense and more tightly constrained to the central axis. A detailed schematic diagram of a vertical cross section through a composite depression is also presented, showing its inherent asymmetric structure.
\end{abstract}

\section{Introduction}

The Indian monsoon trough region experiences 3-6 synoptic-scale cyclonic depressions passing through it during the average summer. The majority of these depressions originate over the head of the Bay of Bengal, usually propagating northwestward onto the Indian subcontinent, lasting an average of 4-5 days (Godbole

๑ Denotes Open Access content.

Corresponding author address: Kieran M. R. Hunt, Department of Meteorology, University of Reading, Earley Gate, P.O. Box 243, Reading RG6 6BB, United Kingdom.

E-mail: k.hunt@pgr.reading.ac.uk
1977; Saha et al. 1981; Sarker and Choudhary 1988; Stano et al. 2002).

The India Meteorological Department imposes the criterion that depressions must have surface winds greater than $8.5 \mathrm{~m} \mathrm{~s}^{-1}$, or they are considered a low, and less than $16.5 \mathrm{~m} \mathrm{~s}^{-1}$, else they are considered a cyclonic storm (Saha et al. 1981; Krishnamurthy and Ajayamohan 2010); our discussion shall be limited to depressions, not including lows or cyclonic storms. They are responsible for heavy and extreme precipitation events as well as strong winds.

Detailed investigation of depression structure in and around the Indian monsoon trough region has been performed previously (e.g., Godbole 1977; Ding 1981; Ding et al. 1984; Sarker and Choudhary 1988; Prasad et al. 1990; Stano et al. 2002). Although the largest 


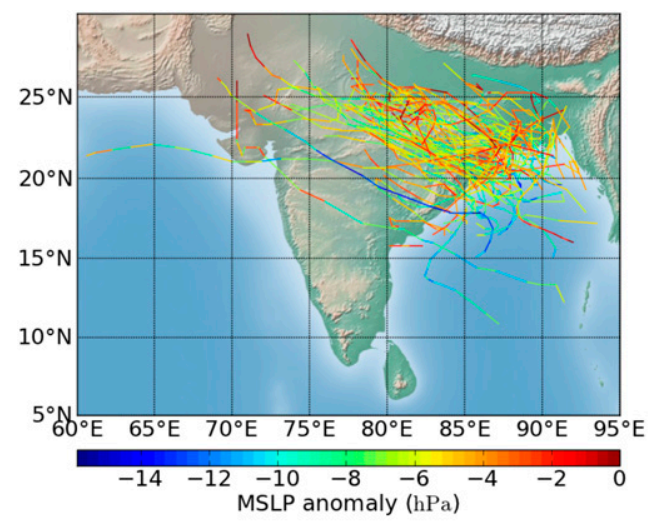

(a)

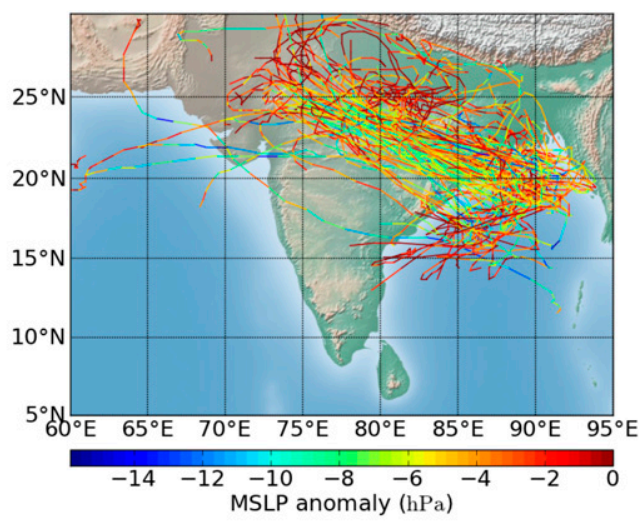

(b)

FIG. 1. Depression tracks from (a) the 106 depressions used in this study and (b) the 98 depressions from the dataset outlined by Hurley and Boos (2015) that fulfill our location criteria. Note that because Hurley and Boos (2015) also included the parts of the depression tracks where they were classified as lows, their tracks appear longer. Color indicates depression intensity using SLP anomaly to a 21-day running mean.

composite generated was of 40 depressions (split into four categories of intensity) by Prasad et al. (1990), they only considered wind and included analysis of satelliteimaged cloud cover on a case-study basis. Sarker and Choudhary (1988) analyzed a number of variables (temperature, moisture, winds, vorticity) of a 27-depression composite based on events during 1961-74, but their data were interpolated from a relatively sparse array of radiosonde stations, all over land. More recently, Stano et al. (2002) conducted hydrometeor analysis on three depressions from 1999.

With the advent of extensive satellite and reanalysis datasets, a truly thorough analysis of a large depression composite over land and sea has now become a possibility. Hurley and Boos (2015) considered a 117-depression composite for 1979-2013, but they did not go into specific detail, instead considering the worldwide climatology of monsoon depressions and examining the winds, potential temperature, and potential vorticity of Indian monsoon depressions. Boos et al. (2015) looked at a potential vorticity analysis of the same dataset. Their analysis also contains more depressions because they consider those originating over the Arabian Sea and inland, whereas we do not.

Here, newly developed feature tracking software was applied to reanalysis data over 36 years (1979-2014), recovering 106 depressions (Fig. 1a) that generally initiated in the Bay of Bengal and made landfall on the Indian subcontinent. These tracks were corroborated with the Indian Meteorology Department (IMD) Cyclone and Depression eAtlas (http://www.imdchennai.gov.in/cyclone_eatlas. $\mathrm{htm}$ ). Thirty-four of these occurred between 1999 and 2013 and thus fall within the Tropical Rainfall Measuring Mission (TRMM) regime (Kummerow et al. 1998).
We will analyze horizontal and vertical structure of the composite depression and compare the structure and dynamics of depressions when situated over ocean and land, as well as the influence of large-scale forcing from modes of intraseasonal and interannual variability on depression strength and structure. An outline of the data and methodology is given in section 2 . We analyze horizontal cross sections of the composite monsoon depression in section 3, looking at both satellite-based and reanalysis data. In section 4 we then look at vertical cross sections of the composite.

Subsequently, we look at local variability within the composite in section 5 and also look at how intraseasonal and interannual modes of variability affect depressions in section 6, investigating the effects of ENSO (section 6a), the Indian Ocean dipole (section 6b), and the activebreak cycle of the monsoon itself (section 6c). We finally conclude in section 7 .

\section{Methodology}

\section{a. Data}

\section{1) Tropical Rainfall Measuring Mission}

The Tropical Rainfall Measuring Mission comprises four satellite-based precipitation-related instruments that have been in orbit since November 1997, from which both raw and gridded datasets are produced (Kozu et al. 2001). For our analysis, we use the 3B42 gridded product (version 7), which derives from the onboard IR scanner. The product consists of 3-hourly gridded $0.25^{\circ} \times 0.25^{\circ}$ surface precipitation over the latitude range $50^{\circ} \mathrm{N}-50^{\circ} \mathrm{S}$ (Huffman et al. 2007, 2010; Liu 
et al. 2012), with a nominal intensity resolution of $0.7 \mathrm{~mm} \mathrm{~h}^{-1}$ (Kozu et al. 2001). The advantage of the 3B42 algorithm product is its calibration and merging with products from a number of other IR-based precipitation satellites: Geostationary Meteorological Satellite (GMS), GOES-East, GOES-West, Meteosat-7, Meteosat-5, and NOAA-12. When compared to a climatology of surface observations, TRMM 3B42 performs well, although it tends to underestimate both low- and high-rainfall rates, generally slightly overestimating overall (Prakash and Gairola 2014) and significantly underestimate rainfall over the Western Ghats (Nair et al. 2009).

\section{2) ERA-INTERIM REANALYSIS}

European Centre for Medium-Range Weather Forecasts ERA-Interim reanalysis data (Dee et al. 2011) that we use are the surface analysis for horizontal compositing and the pressure level analysis for both horizontal and vertical (see section 4) compositing. Our analysis uses the 27 output pressure levels from 1000 to $100 \mathrm{hPa}$ and the horizontal output resolution of approximately $0.7^{\circ} \times 0.7^{\circ}(\mathrm{N} 128)$. In this reanalysis, the cloud cover field is purely model derived-it is calculated by summing the contributions of stratiform and convective cloud covers, respectively. Stratiform cover is predicted from local relative humidity (Sundqvist et al. 1989), whereas convective cover is predicted from parameterization of convection (Slingo 1987).

\section{b. Tracking software}

To automate the collection of data on depressions, feature tracking software was written, as summarized in Fig. 2. Because of the complex orography north of the trough and the sea-to-land transitions of depressions, we could not rely solely on any particular criterion, so a filtering procedure was carried out on relative vorticity, geopotential height, and wind speed.

For each 6-hourly time step, the tracking software finds a relative vorticity maximum at $800 \mathrm{hPa}$, above a threshold of $1 \times 10^{-5} \mathrm{~s}^{-1}$. It then eliminates all cases without a nearby synoptic-scale surface low (negative surface pressure anomaly relative to a 21-day climatology), or failing the wind threshold criterion for depressions. Use of the $800-\mathrm{hPa}$ level reduces boundary layer effects from the Himalayas while sampling the vortical core. Consecutive reanalysis outputs containing depression candidates are then connected, as long as the candidate has not moved too far between frames, and locations, times, and headings are recorded.

Filtering is applied to ensure consecutive relative vorticity $(\zeta)$ maxima are attributable to the same event and that the events last a minimum of $24 \mathrm{~h}$. Before further

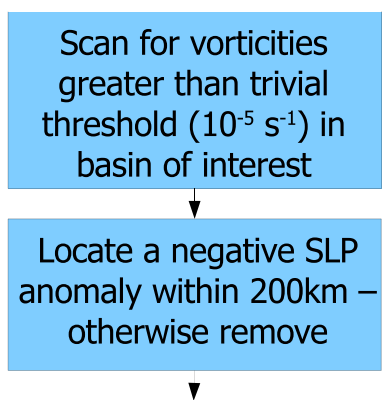

Remove candidates that do not have surface wind speed $>8.5 \mathrm{~m} \mathrm{~s}^{-1}$ within $400 \mathrm{~km}$; and those remaining that have $>16.5 \mathrm{~m} \mathrm{~s}^{-1}$ within $500 \mathrm{~km}$

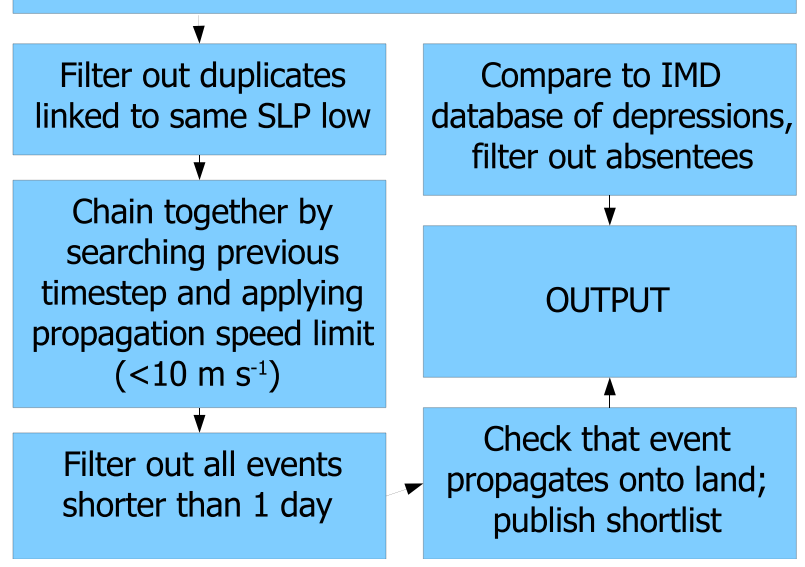

FIG. 2. Flowchart outlining the key stages of the tracking algorithm.

analysis, the 6-hourly fields are smoothed with a 12-h moving window to reduce noise. Those depressions that were not in the IMD eAtlas were then removed. For verification, monsoon depressions from the Hurley and Boos (2015) dataset with the same spatial criteria are shown in Fig. 1b, with whom, for the same period, we share some $90 \%$ of events. The tracks from their dataset appear longer because they also include the parts of depression tracks where they were only strong enough to be considered a monsoon low (as demonstrated by the coloring). Prajeesh et al. (2013) considered both the IMD depression archive and the dataset of Sikka (2006) and showed that in each, a statistically significant decline in frequency exists. This was challenged, however, by Cohen and Boos (2014), who used several independent datasets (including that of Hurley and Boos 2015) to show that this might not be case, consequently calling into question the validity of the downward trend in the IMD dataset.

The mean depression heading in our composite was $332^{\circ}$; neglecting eastward-propagating depressions gives a mean heading of $295^{\circ}$. The mean propagation speed was $2.75 \mathrm{~m} \mathrm{~s}^{-1}$, and all depressions that fit our criteria initiate and terminate between $11^{\circ}$ and $27^{\circ} \mathrm{N}$, and between $62^{\circ}$ and $94^{\circ} \mathrm{E}$. 


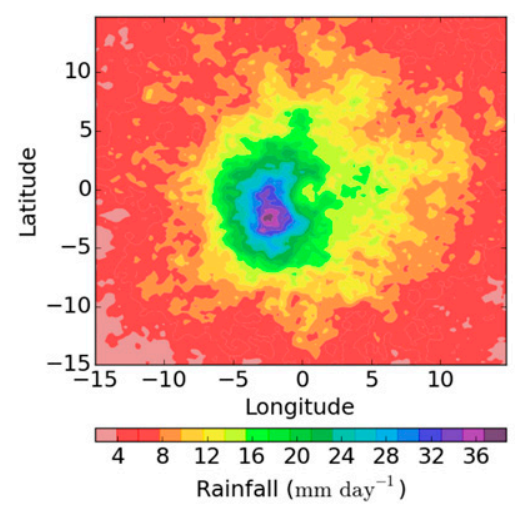

(a)

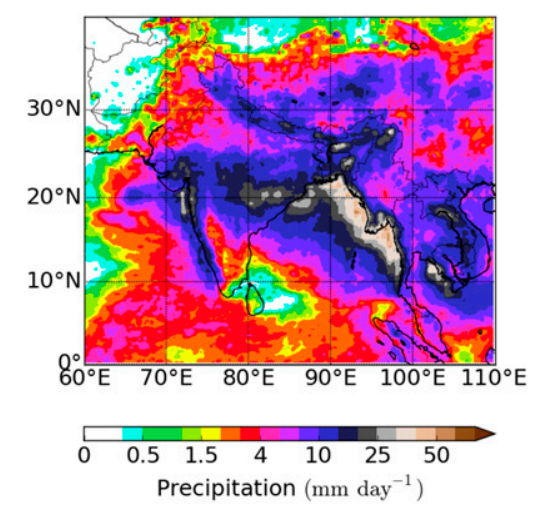

(b)

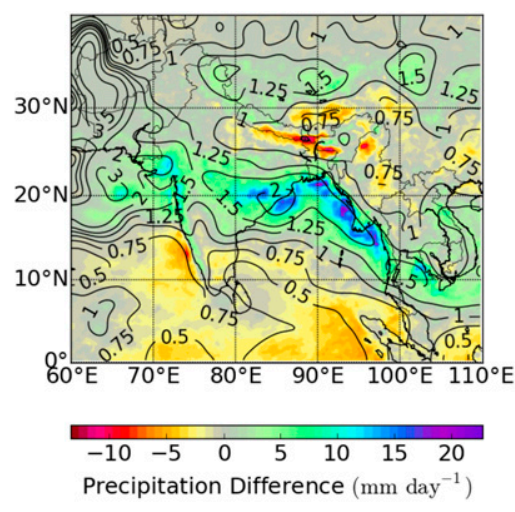

(c)

FIG. 3. Composite precipitation data from TRMM for the 34 depressions in the period 1998-2013. (a) Rotated, composited, systemrelative precipitation $\left(\mathrm{mm} \mathrm{day}^{-1}\right)$ - the direction of propagation is upward on the page; (b) average precipitation $\left(\mathrm{mm} \mathrm{day}^{-1}\right)$ for South Asia on depression days; and (c) the difference between depression days and the boreal summer mean (colors) and their ratio (lines).

Next, each depression was centralized to $0^{\circ}$ latitude, $0^{\circ}$ longitude and reoriented using output heading data to create a forward (northward) -propagating composite. Rotation during compositing allows us to determine system-relative features and mitigates orographic artifacts (e.g., forced ascent by the Eastern Ghats). We use the term "relative" with compass directions to describe sectors of the depression; relative north being the direction of propagation. The resulting array was then sliced horizontally through different pressure levels to reveal internal structure of the composite depression. Apart from variables that are usually defined at the surface, the chosen pressure levels are usually 850 and $200 \mathrm{hPa}$.

\section{c. Significance testing}

We have sufficient data to perform significance testing on the total composite and an intercomparison within the composite to ensure the robustness of our results.

1) A Student's $t$ test is performed to see whether the composite state significantly differs from the mean state (i.e., the summer climatology). Areas where a $95 \%$ confidence threshold is not satisfied are colored gray in these figures.

2) Subsets are tested against their superset composite (e.g., if we propose that a variable $\chi$ can be meaningfully split into subset fields $\chi_{i}$, we would test $\chi_{i}$ against $\chi$, rather than the background climatology). This testing is performed by bootstrap resampling the superset (see, e.g., Efron 1979) and producing 10000 random samples replicating the size of the subset. The subset and random samples are then individually composited and each grid point in the subset is placed in the respective gridpoint distribution from the random samples. For $95 \%$ confidence that the subset is significantly different from its superset, we must return a percentile either below $2.5 \%$ or above $97.5 \%$.

3) On pairs of subsets we perform an analogous method, except the bootstrapping produces 10000 pairs of random samples (again, each with the same sample size) and differences each pair to produce the distribution of differences for comparison with the observed intersubset differences.

\section{d. Choosing a suitable climatology}

It is important to choose an appropriate climatology (e.g., a summer mean, a daily mean, or a fixed-length running mean) for our analysis on depressions as anomalies to the monsoon background state. When considering the full composite, as in sections 3 and 4, we bear in mind that not having a significant trend in depression frequency across the summer entitles us to make an arbitrary choice of climatology. This was confirmed with several sensitivity experiments on the composite (not shown). When we discuss time-dependent large-scale forcings, this assertion is no longer valid; thus, if we are to use a climatology in that analysis, it must be a running mean one so as to capture the background effect of the forcing.

\section{Composite horizontal structure}

In this section we describe the horizontal composite structure of the depressions, first looking at precipitation and then reanalysis fields.

\section{a. Precipitation}

TRMM precipitation data were composited for 1998 2013, the range of the dataset; Fig. 3a shows the average 


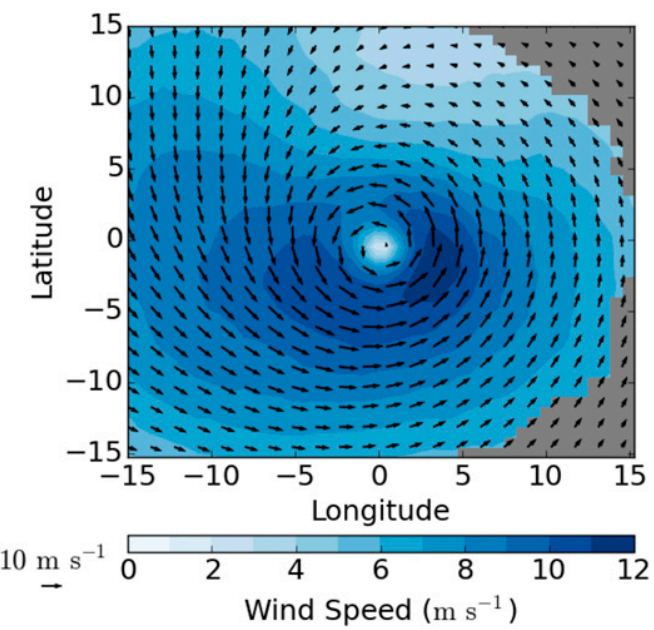

(a) Composite wind structure.

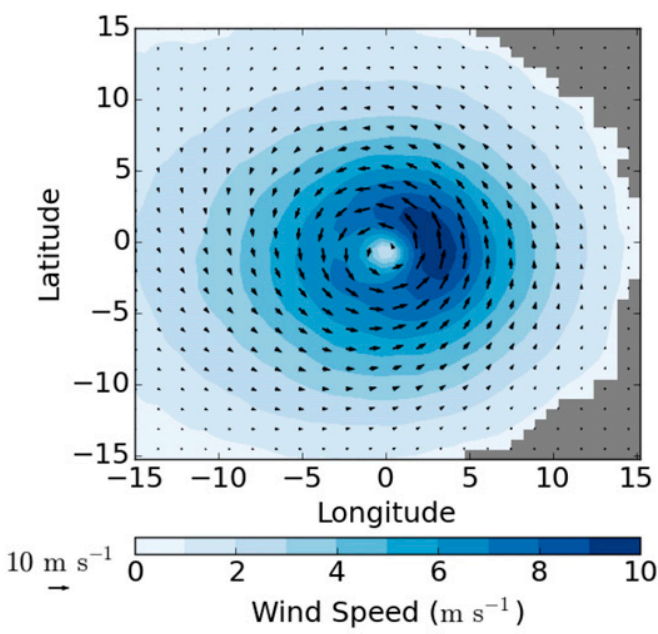

(b) Composite wind structure with background flow removed.

FIG. 4. Wind speed at $850 \mathrm{hPa}\left(\mathrm{m} \mathrm{s}^{-1}\right)$ in colored contours, with wind vectors overlaid, for the 106-depression composite, using ERA-Interim reanalysis data over 1979-2014 for (a) the full composite and (b) the composite as an anomaly to the summer mean circulation. Colored contours are grayed out where the composite does not significantly differ from the climatology at the $95 \%$ level.

precipitation for all 34 depressions that initiated in the Bay of Bengal in this period. The most intense rainfall rate found during any 3-hourly TRMM time step was $68.4 \mathrm{~mm} \mathrm{~h}^{-1}$ (1.6 $\mathrm{m} \mathrm{day}^{-1}$ equivalent). Comparing this to the highest "daily mean" intensity in the 34-depression composite $\left(38.6 \mathrm{~mm} \mathrm{day}^{-1}\right)$ shows the sparsity and unpredictability of such intense events.

The location of the average rainfall maximum to the relative southwest agrees with Godbole (1977) and Yoon and Chen (2005). That the rainfall is most intense to the left of the central track has been known for some time (Ramanathan and Ramakrishnan 1933). Mooley (1973) provided a good summary of the literature on why this might be the case, including hypotheses from Roy and Roy (1930), Ramanathan and Ramakrishnan (1933), Mull and Rao (1949), Desai (1951), and Petterssen (1956). He came to the conclusion that a combination of factors are responsible: (i) the southwest axial tilt of the depression core with height, (ii) a convergence maximum in the relative west-southwest sector, and (iii) cyclonic mixing of warm, southwesterly air from the Arabian Sea with the generally cooler, easterly monsoon flow. Inspection of the distribution for "extreme" rainfall events (not shown) indicates that the probability for higher rainfall rates is increased near the composite maximum, although the highest intensities are seen sporadically outside this area and are probably usually unrelated to the depression itself.

Figure $3 \mathrm{~b}$ shows the total rainfall across India for depression days, and Fig. 3c shows the anomaly of this relative to the summer mean for the TRMM period. The wettest anomalies are found around coastal areas (particularly the Bay of Bengal), and wet anomalies persist across much of the trough region, displaced from the track density (see Fig. 1a) several degrees to the southwest, as the precipitation structure (see Fig. 3a) predicts. There are also dry anomalies over the Himalayan foothills and northern Indian Ocean, creating something of a "wet" channel with dry edges, implying that a passing depression drags in surrounding moist air from a large area where precipitation is suppressed by atmospheric subsidence.

\section{b. Reanalysis fields}

We next explore dynamic and thermodynamic fields from reanalysis to help elucidate the depression structure.

First we will examine wind: Fig. 4 shows $850-\mathrm{hPa}$ wind speed and direction for the composite depression (Fig. 4a). We see the maximum wind intensity is in the relative southeast, approximately $3^{\circ}$ away from the center, whereas a local minimum occurs at the center (along with the streamfunction minimum; not shown), as in the eyes of more intense systems such as tropical cyclones. Removal of the background climatological winds (Fig. 4b) shows the perturbation the depression makes to the monsoon: the structure is more circular since the asymmetrical presence of the climatological monsoon winds at $850 \mathrm{hPa}$ is now absent-particularly in the relative south and west sectors, and we see an intensification of the winds in the relative east due to the presence of the Himalayas via the image vortex mechanism described in 


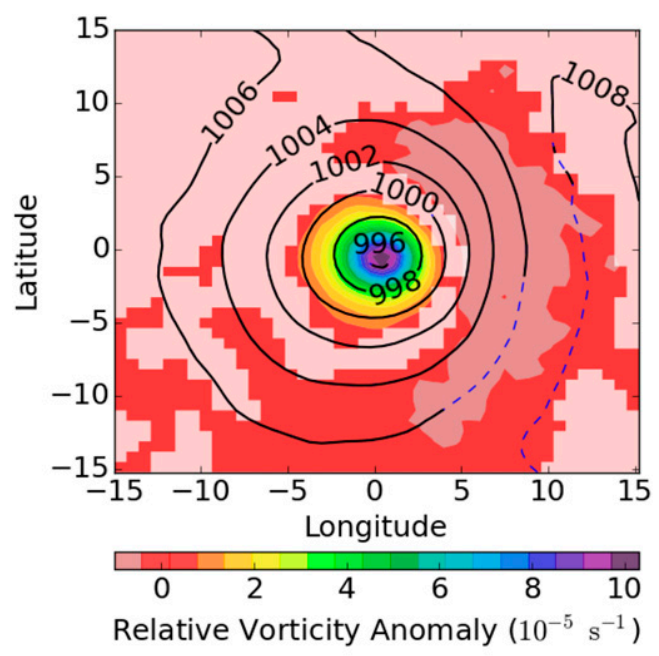

(a) Surface Pressure with relative vorticity $(\zeta)$ at $850 \mathrm{hPa}$.

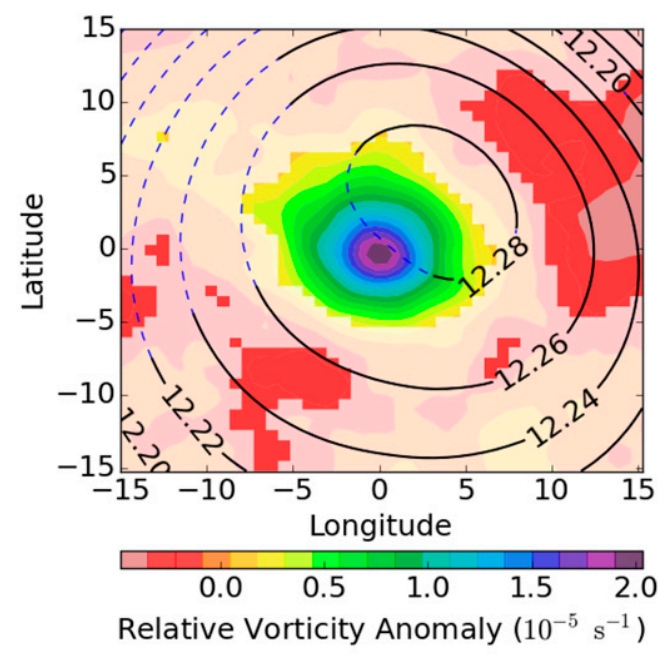

(b) Geopotential Height and $\zeta$ at $200 \mathrm{hPa}$.

FIG. 5. Composite relative vorticity $\left(10^{-5} \mathrm{~s}^{-1}\right)$ shown as shading in the (a) lower and (b) upper troposphere along with line contours indicating surface pressure in (a) and $200-\mathrm{hPa}$ geopotential height in (b). Positive vorticity indicates cyclonic, counterclockwise rotation. Line contours become blue dashes where the composite does not differ significantly from the climatology at the $95 \%$ level; likewise, colored contours are reduced to $20 \%$ intensity.

Hunt and Parker (2015, manuscript submitted to Quart. J. Roy. Meteor. Soc.). The overall wind speed pattern is very similar in shape, although with reduced intensity, to that described in Catto et al. (2010) for extratropical cyclones and is also similar to that of the smaller composites described in Godbole (1977) and Prasad et al. (1990).

Above $200 \mathrm{hPa}$ (not shown), the depression contributes a weak $\left(<4 \mathrm{~m} \mathrm{~s}^{-1}\right)$ anticyclone to the much stronger $\left(>20 \mathrm{~m} \mathrm{~s}^{-1}\right)$ monsoonal jets at this height. There is an upper-level wind speed minimum above the core, as there is above tropical cyclones (DeMaria 1996). The background flow provides the vertical shear that restricts further development of the depressions into cyclones in midsummer (e.g., Ramage 1959; DeMaria 1996) so that tropical cyclones in the northern Indian Ocean have a bimodal distribution with maxima in May and November and minima in February and August (Kikuchi and Wang 2010).

We can now examine two more of the variables used in tracking the depressions: relative vorticity and pressure (Fig. 5). At $850 \mathrm{hPa}$ (Fig. 5a), the negative relative vorticity imparted to the depressions by the presence of the Himalayas (friction and vortex squashing) is notable (pink contour level) in the relative vorticity field. Indeed, depressions at latitudes nearing the foothills are shorter lived (Fig. 1a), and north of a certain latitude, only depressions from the more favorable La Niña years (not shown) tend to persist, since the Bay of Bengal has greater relative vorticity and relative humidity (Felton et al. 2013). The relation between depression variability and ENSO will be discussed further in section $6 a$.
At $200 \mathrm{hPa}$ (Fig. 5b) the expected anticyclonic pattern is clear: only the immediate center has positive relative vorticity, and from just a few degrees out this becomes negative (anticyclonic), again with influence of the $\mathrm{Hi}$ malayas in the relative northeast sector where vorticity is most negative. This is further supported by the presence of a large shallow area of high geopotential over the relative northeast sector.

Two horizontal temperature slices are given in Fig. 6. At the surface, the low-level cold-core nature of the composite is clear, with a temperature minimum in the relative southwest sector. There is a consistently steep rise in temperature away from the center until a radius of approximately $7^{\circ}$, eventually becoming a slightly anomalously warm environment. At $350 \mathrm{hPa}$, the anomaly has opposite sign, becoming warm compared to the climatology. This warm maximum is located slightly relative southward of the center and has similar magnitude and gradient to its surface companion. However, there is greater asymmetry: the anomaly is nearly half a degree colder in the lee of the depression than ahead of it.

We now turn to relative humidity and analyzed cloud cover (Fig. 7). This total cloud cover bears some similarity with that of the extratropical cyclones in the atlas defined by Dacre et al. (2012). There is a maximum composite cloud cover of $87 \%$ in the relative southwest sector, near the precipitation maximum. There is greater cover in the lee of the depression, likely owing to the larger quantity of moisture and stronger surface winds there than in the advance of the depression. 


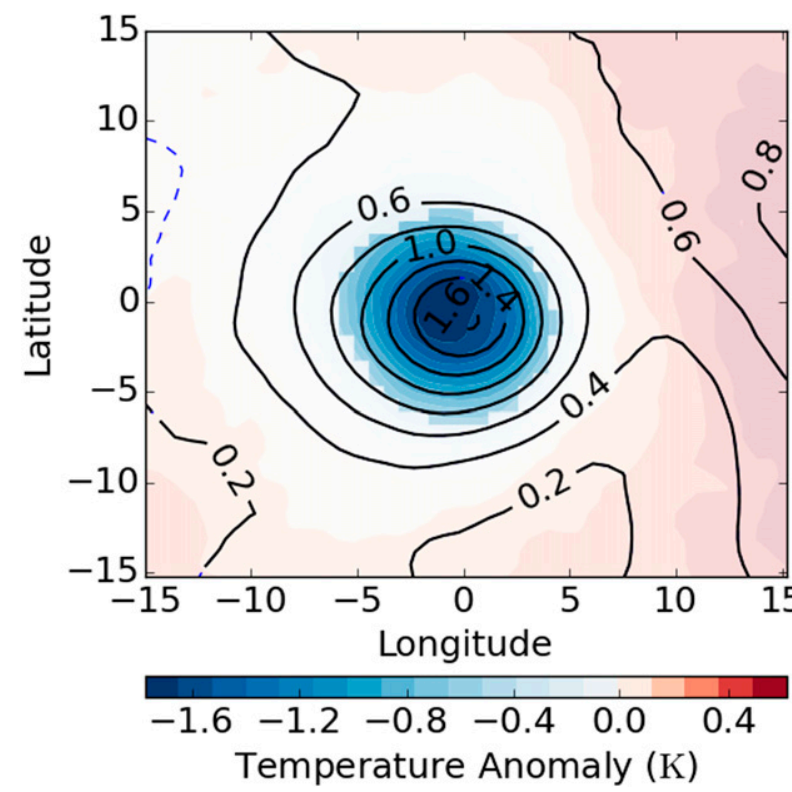

FIG. 6. The 2-m temperature anomalies (K) in colored contours and $350-\mathrm{hPa}$ temperature anomalies (K) in line contours. Both shown as anomalies to the boreal summer mean.

The $850-\mathrm{hPa}$ relative humidity field features a maximum in the relative southwest sector, as with rainfall and cloud cover. We see that the humidity falls away more rapidly ahead of the depression than behind it, since the depressions tend to have the Bay of Bengal environment behind them and the drier Indian subcontinent ahead.

We also analyzed surface heat exchanges and boundary layer processes (not shown); we caution that these are entirely modeled products within the reanalysis and thus have higher uncertainty than previous composite fields. However, our findings are in line with theoretical results: we find the boundary layer height drops sharply near the center to around $500 \mathrm{~m}$, from the climatological value of $800 \mathrm{~m}$. This finding couples with a reduction in magnitude of both sensible and latent surface heat fluxes: values are reduced from the typical climatologies of $\sim 30$ and $\sim 100 \mathrm{~W} \mathrm{~m}^{-2}$ to $\sim 8$ and $\sim 75 \mathrm{~W} \mathrm{~m}^{-2}$ over the center, respectively.

\section{Composite vertical structure}

Stano et al. (2002) estimate the vertical extent of a monsoon depression to be in the region of $12-15 \mathrm{~km}$ (200-120-hPa pressure height) based on radar hydrometeor data from TRMM, so we shall look at vertical cross sections over the 27 available ERA-Interim pressure levels from 1000 to $100 \mathrm{hPa}$. We start by considering the overall 106-depression composite before looking at the effects of larger-scale monsoon variability. ERAInterim repeats values for the lowest atmospheric level

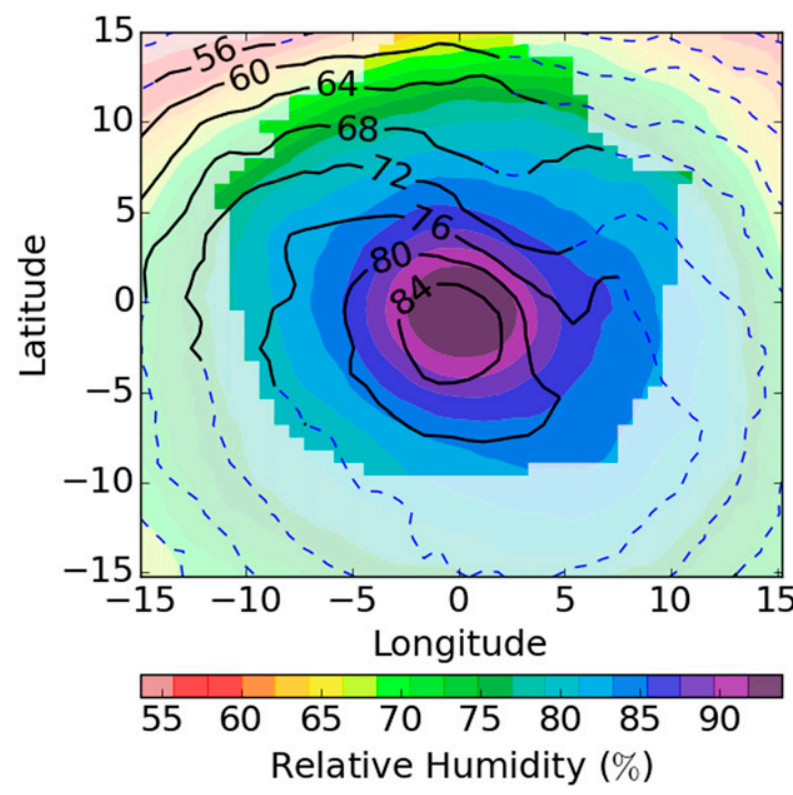

FIG. 7. Composite relative humidity (\%) at $850 \mathrm{hPa}$ in colored contours with total cloud cover (\%) in line contours. Statistical significance is displayed as in Fig. 5.

over orography at all subsurface levels down to $1000 \mathrm{hPa}$; those data are not composited. The vertical composites are drawn above the zero-latitude line in a horizontal composite using the central grid point in the north-south direction, with relative west on the left and relative east on the right.

\section{a. Moisture}

Analysis of the vertical distribution and transport of moisture in the composite serves to verify the rainfall structure and provide further insight into the moist mechanisms of the depression.

Relative humidity (Fig. 8a) slightly resembles the structure of cloud cover: two strong maxima, one just above the surface at the center, and one much nearer the tropopause. There is again (as with, e.g., divergence) a relative westward axial tilt persisting until the axial minimum at approximately $350 \mathrm{hPa}$. The $90 \%$ isohume near the surface is large, spanning a cross-sectional area of approximately $1500 \mathrm{~km}^{2}$ (a volume of over $800000 \mathrm{~km}^{3}$ assuming azimuthal symmetry), indicating the composite depression has a vast, nearly saturated core within it.

It is well known (e.g., LeMone et al. 1998; Cetrone and Houze 2006) that the tropical atmosphere has a high relative humidity, so we should explore exactly how much moisture the depression adds to the environment. The composite structure of relative humidity as an anomaly to the climatology (not shown) again shows westward tilt with height, corroborating the rainfall asymmetry discussed in section $3 \mathrm{a}$. In the middle and lower troposphere, 


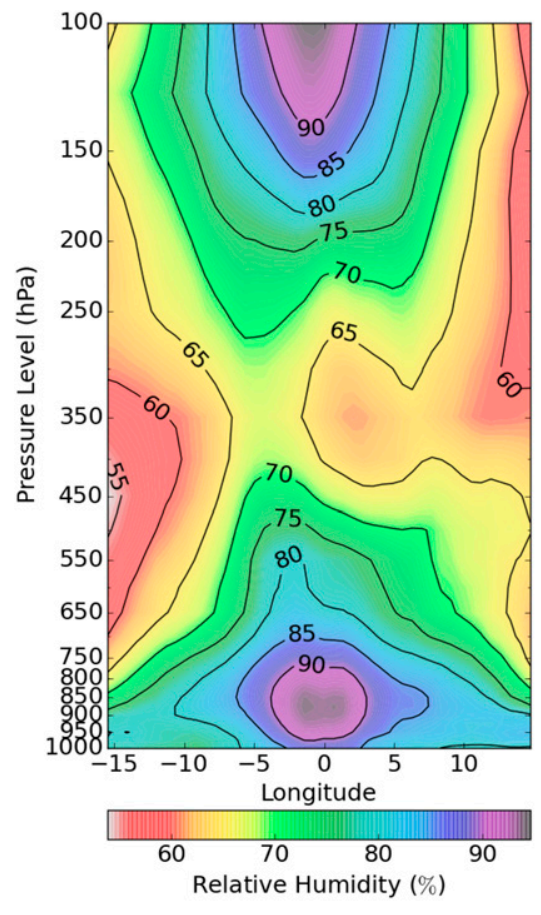

(a) Relative humidity

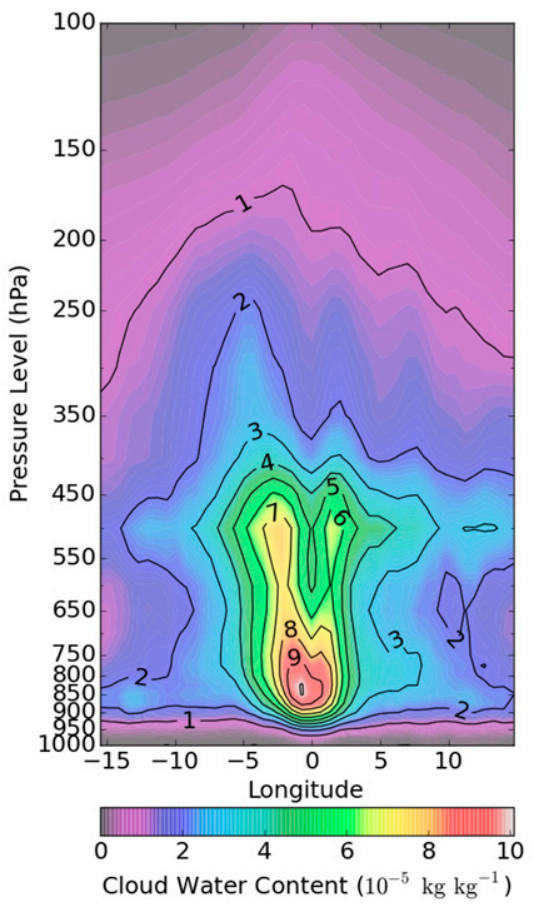

(b) Cloud water content

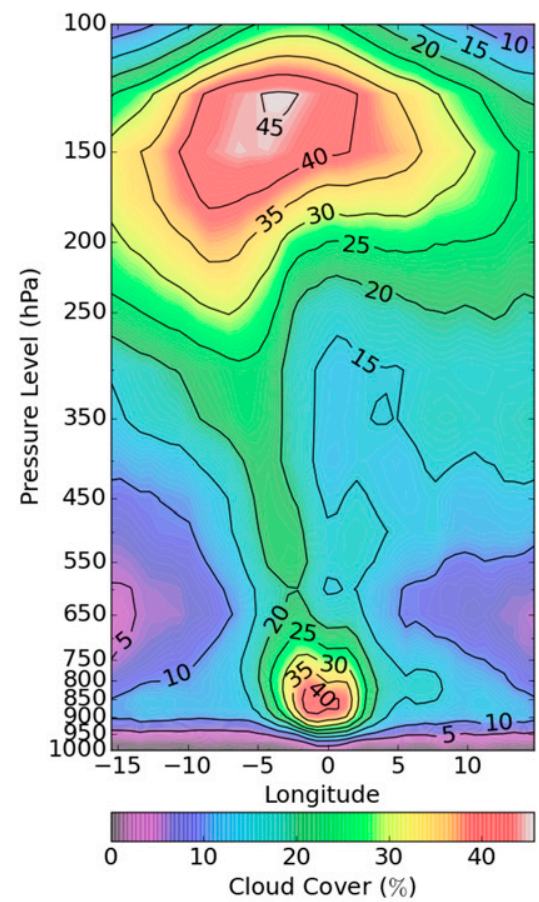

(c) Cloud cover

FIG. 8. (a) Relative humidity (\%), (b) cloud water content $\left(10^{-5} \mathrm{~kg} \mathrm{~kg}^{-1}\right.$; the summation of liquid and ice contributions), and (c) cloud cover (fraction of unity) as functions of pressure levels as viewed on a plane normal to the direction of depression propagation. Direction of propagation is into the page. Colored contours are grayed out where the composite does not significantly differ from the climatology at the $95 \%$ level.

the depression contributes around $10 \%-15 \%$, resulting in a nearly saturated environment.

\section{b. Cloud features}

Figure $8 \mathrm{~b}$ shows the vertical structure of cloud water content (CWC) across the depression. Cloud products from ERA-Interim are heavily reliant on the reanalysis model, but since they are constrained by other observations we may have some confidence in their patterns. CWC is a proxy for cloud type (Hess et al. 1998; Rosenfeld and Lensky 1998), with the threshold for cumulonimbus at $7 \times 10^{-5} \mathrm{~kg} \mathrm{~kg}^{-1}$ and stratocumulus at $3.5 \times 10^{-5} \mathrm{~kg} \mathrm{~kg}^{-1}$. We can identify a cumulonimbus base at about $900 \mathrm{hPa}$, and at around $550 \mathrm{hPa}$ clouds are clearly more dense away from the depression center, again lending evidence to a weak, incomplete eyelike structure. Above approximately $450 \mathrm{hPa}$, most cloud mass comprises ice. The vertical structure of cloud cover (Fig. 8c) reveals two distinct regions of large cloud cover: a maximum near $850 \mathrm{hPa}$ surrounding the center, and an upper-level maximum, to the relative west of the center, near $150 \mathrm{hPa}$. These are the clouds that dominate the visible-light satellite pictures, anticyclonically rotating cirrus, and cirrostratus clouds (Houze 2010). The general shape resembles that of a classic cumulonimbus cross section (with resolved low-level cloud and an anvil fed by deep convection/ascent), and there are potential rainbands visible in the relative east flank.

\section{c. Potential vorticity and circulation}

The vertical structure of potential vorticity (Fig. 9a) has a bimodal maximum core of a little over $10^{-6} \mathrm{~K} \mathrm{~m}^{2} \mathrm{~kg}^{-1} \mathrm{~s}^{-1}$ extending from approximately 750 to $450 \mathrm{hPa}$. There is a minimum aloft, at approximately 250-200 hPa before the effect of the high-PV stratosphere becomes apparent.

Tangential wind speed anomaly (Fig. 9b) follows approximately what we might expect from a classical cyclonic structure, with two lobes of local maximum intensity found slightly above the surface $(\sim 850 \mathrm{hPa})$ and at a distance of several hundred kilometers from a relatively calm center. The axial tilt to the relative west is mentioned both above and in Godbole (1977). Approaching the tropopause, the anticyclone is considerably affected by the strong zonal monsoon flow $\left(\sim 20 \mathrm{~m} \mathrm{~s}^{-1}\right)$, and the axis starts to tilt instead to the relative northeast (corroborated by the horizontal slice at $200 \mathrm{hPa}$; see 


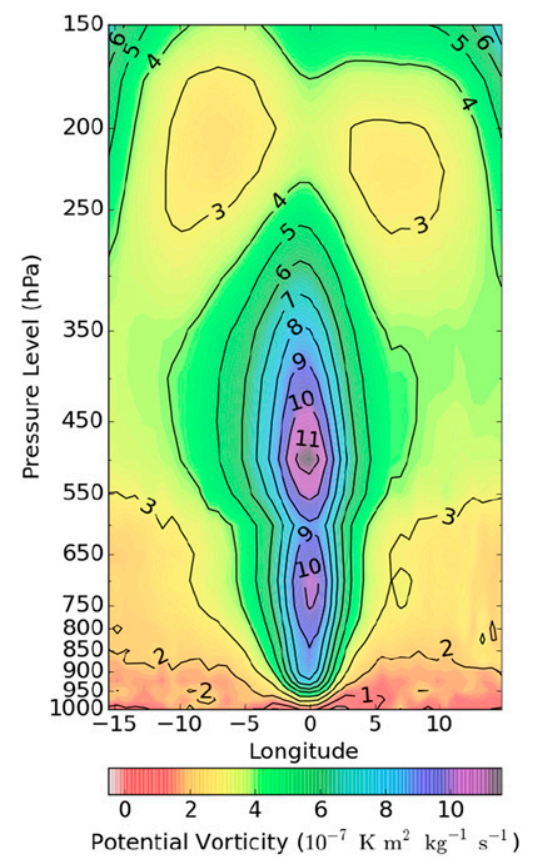

(a) Potential vorticity

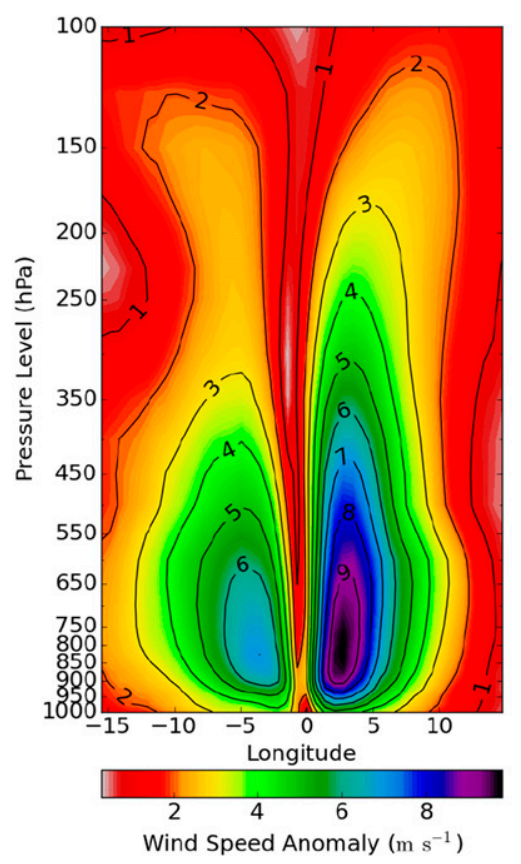

(b) Tangential wind speed

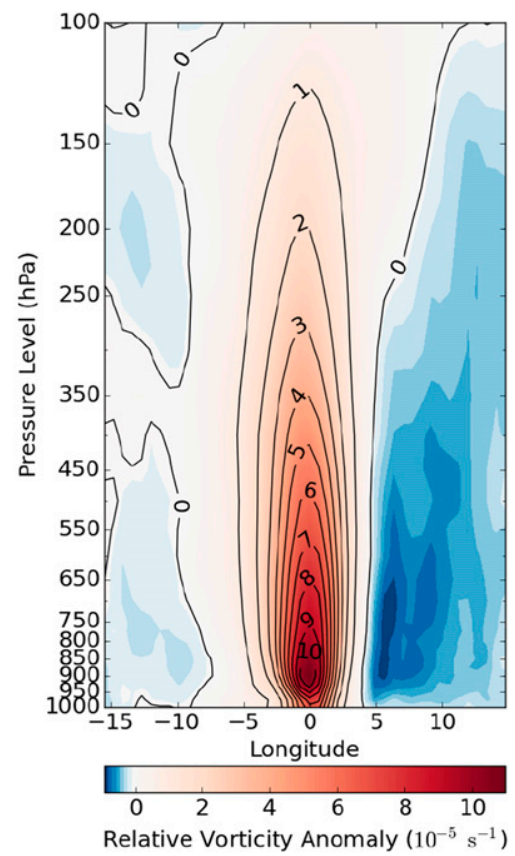

(c) Relative vorticity

FIG. 9. View and significance as defined in Fig. 8: (a) potential vorticity $\left(10^{-1} \mathrm{~K} \mathrm{~m}^{2} \mathrm{~kg}^{-1} \mathrm{~s}^{-1}\right)$, (b) tangential wind speed ( $\mathrm{m} \mathrm{s}$ values going into the page, negative coming out), and (c) relative vorticity $\left(10^{-5} \mathrm{~s}^{-1}\right)$, all viewed as anomalies to the summer climatology. Note the different $y$ axis for (a).

Fig. 5b). When the climatology is not removed, the tangential wind speed structure strongly resembles that shown in Sikka (1977) based on work by Sikka and Paul (1975) on a composite of July/August depressions in 1966-70 and the composite of Godbole (1977).

The vertical structure of relative vorticity anomaly is given in Fig. 9c. It has a very symmetric form, with a maximum intensity found at approximately $900 \mathrm{hPa}$. Godbole (1977) reported a similar shape, but with a slightly more elevated maximum, at approximately $800 \mathrm{hPa}$. Also visible is the very slight relative westward axial tilt also observed by Godbole (1977). The anticyclonic behavior expected near the tropopause is apparent away from the center (as seen in Fig. 5b). Again, the imposition of negative vorticity from the Himalayas in the relative east is visible.

Vertical velocity (Fig. 10) has an axial tilt and slightly bilobal structure extending into the midtroposphere. There is weak ascent at the surface, but parcels are rapidly accelerated near the core, reaching a peak of over $0.2 \mathrm{~Pa} \mathrm{~s}^{-1}$ (corresponding to $2.0 \mathrm{~m} \mathrm{~s}^{-1}$ ) slightly to the relative west of the center at approximately $800 \mathrm{hPa}$. The ascent slowly decelerates thereafter and the bilobal shape becomes asymmetric, favoring the relative west side, coming almost to a stop by the tropopause. Figure 10 also shows the zonal circulation through the center of the composite. Perhaps most apparent is the strong blocking signal at most heights from the $\mathrm{Hi}$ malayas in the east - a considerable majority of the wind inflow at the center comes from the west, although outflow aloft is roughly symmetric. The strong easterly inflow near the center and the surface could be the result of cyclonic flow being suppressed near the Himalayas and results in slightly easterly flow throughout the axis up to the 350-hPa level (potentially supporting the westward axial tilt). Divergence (not shown) is rather noisy, although there is an area of concentrated, strong convergence at the center near the surface; near the tropopause, where the outflow is situated, there is an area of weak divergence (approximately 5 times weaker than the convergence at the surface), slightly to the relative west of the center.

\section{d. Moisture flux}

For horizontal moisture transport in the composite, we must consider sources of both water and advection and do so by separating the specific humidity flux vector into contributions from both the mean state and the depression-induced perturbation; that is,

$$
q \mathbf{v}=\bar{q} \overline{\mathbf{v}}+q^{\prime} \overline{\mathbf{v}}+\bar{q} \mathbf{v}^{\prime}+q^{\prime} \mathbf{v}^{\prime}
$$




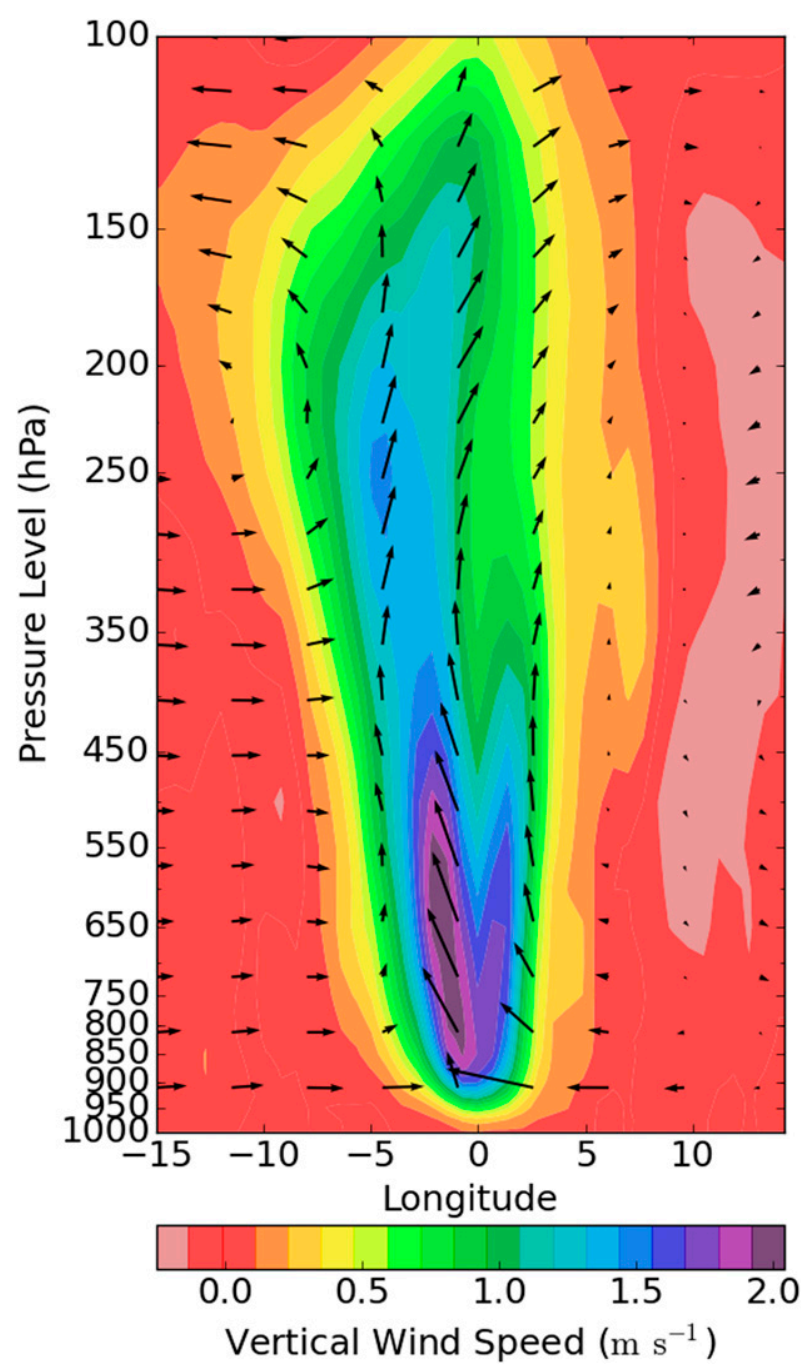

FIG. 10. View and significance as defined in Fig. 8. Vertical wind speed $\left(\mathrm{m} \mathrm{s}^{-1}\right)$ and quivers for vertical-zonal wind at the crosssectional boundary. Note that the quivers follow actual composite winds and are not affected by the horizontal-vertical axis ratio of $\sim 200$.

where $q$ is specific humidity, $\mathbf{v}$ is the wind vector, the overbar represents the mean state of the variable (i.e., the climatology), and the prime represents the depression anomaly to the mean state (i.e., the perturbation). The presence of a depression contributes only a fraction of the total moisture present in the composite (not shown), and the base monsoon state contributes little to the depression winds near the center (Fig. 4); therefore, we might expect the most significant contribution on the right-hand side of Eq. (1) to come from the anomalous (i.e., depression induced) advection of climatological moisture $\left(\bar{q} \mathbf{v}^{\prime}\right)$. To confirm this, we examine the structure of each perturbation term (shown in Fig. 11). We see that the greatest contribution indeed comes from $\bar{q} \mathbf{v}^{\prime}$ and that, although the contribution from $q^{\prime} \mathbf{v}^{\prime}$ is roughly a fifth as large, it has greater relative vertical and horizontal extent and a more strongly bifurcated structure.

\section{e. Temperature profile}

The vertical structure of temperature is given in Fig. 12a and is shown (owing to the strong temperature gradient with height) as an anomaly relative to the structure of the boreal summer mean temperature profile. The resulting composite is a cold-core event in the lower troposphere, agreeing with Sarker and Choudhary (1988) and Hurley and Boos (2015), amongst others. Sarker and Choudhary (1988) suggest the reasons for the cold anomaly include dynamical uplift, evaporating precipitation, and radiative cooling. We speculate that Fig. $8 \mathrm{c}$ corroborates the last point, indicating that cloud cover reduces insolation (cooling the lower levels) and blocks outgoing longwave radiation (heating the upper levels) - a mechanism that would be absent if there were the fully developed eye of a tropical cyclone. The warm core aloft is a result of the high instability at lower levels and resulting rapid ascent, coupled with strong latent heating from the high rates of convective precipitation associated with depressions, although its magnitude $(\sim 2 \mathrm{~K})$ is considerably less than that of a tropical cyclone (La Seur and Hawkins 1963; Hawkins and Rubsam 1968; Hawkins and Imbembo 1976; Stern and Nolan 2012).

For comparison, the potential temperature anomaly is shown in Fig. 12b. We see very little difference in the lower levels (i.e., before much lifting has taken place), although a warmer core $(+2,0.4 \mathrm{~K}$ warmer than temperature alone) is present in the midtroposphere, strongly agreeing in shape and magnitude with the composite from Hurley and Boos (2015). The vertical gradient implies that, relative to the climatology, latent heating has the greater effect until $350 \mathrm{hPa}$ while radiative cooling has the greater effect thereafter until the tropopause. The equivalent potential temperature (Fig. 12c) shows the importance of moisture in the depression structure-the maximum has lower altitude (around $650 \mathrm{hPa}$ ) and larger positive anomaly $(\sim 5.8 \mathrm{~K})$.

We categorize the 106 depressions into warm core, neural core, or cold core by calculating the average $1000-\mathrm{hPa}$ temperature anomaly in a $1.5^{\circ}$ box surrounding the center. Using $T_{\text {warm }} \geq 0.75 \mathrm{~K}>T_{\text {neutral }} \geq-0.75 \mathrm{~K}>T_{\text {cold }}$, we count 2,28 , and 76 events, respectively. While SSTs are usually used in the description of tropical cyclones, the significant duration spent by monsoon depressions over land meant that surface air $(1000 \mathrm{hPa})$ temperature provided a more useful measure. The criteria were established by identifying and removing the two warm-core outliers, then fitting a two-Gaussian sum (giving a better 


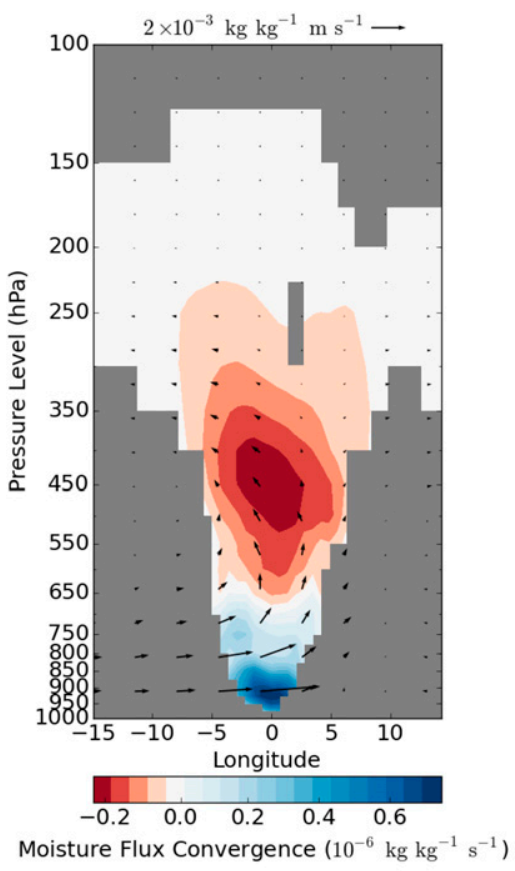

(a) $q^{\prime} \overline{\mathbf{v}}$

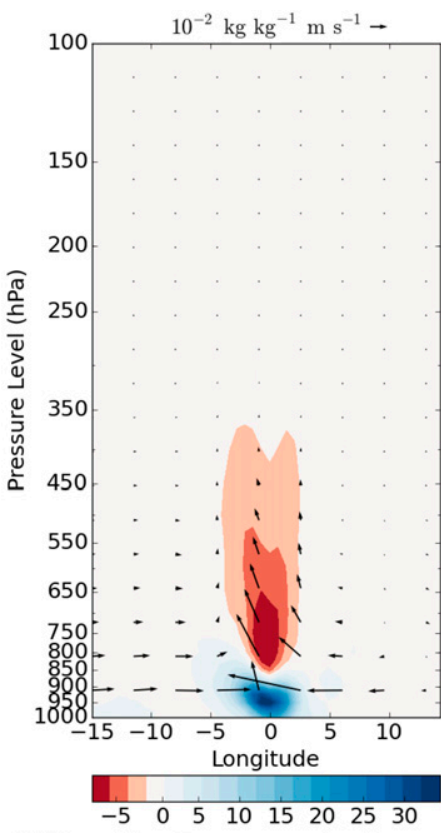

Moisture Flux Convergence $\left(10^{-6} \mathrm{~kg} \mathrm{~kg}^{-1} \mathrm{~s}^{-1}\right)$

(b) $\bar{q} \mathbf{v}^{\prime}$

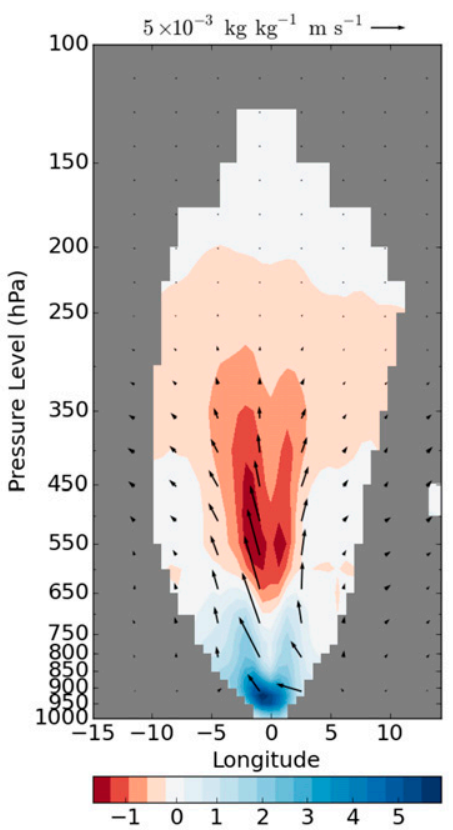

Moisture Flux Convergence $\left(10^{-6} \mathrm{~kg} \mathrm{~kg}^{-1} \mathrm{~s}^{-1}\right)$

(c) $q^{\prime} \mathbf{v}^{\prime}$

FIG. 11. Vertical structure of the three specific humidity flux perturbation terms from Eq. (1) $\left(\mathrm{kg} \mathrm{kg}^{-1} \mathrm{~m} \mathrm{~s}^{-1}\right)$ and associated convergence $\left(\mathrm{kg} \mathrm{kg}^{-1} \mathrm{~s}^{-1}\right)$ in colored contours: (a) the anomalous moisture advected by the climatological wind, (b) the climatological moisture advected by the anomalous wind, and (c) the anomalous moisture advected by the anomalous wind. Colors are grayed where the moisture flux is not significantly different at the $95 \%$ confidence level from a bootstrapped zero-centered distribution derived from differencing random pairs of samples from the composite of $q \mathbf{v}$. Note the differing color scales and unit vectors.

mean-square error than 1) to the distribution of central temperatures, constraining one to be centered on the origin. The strongest cold-core event registered at $-3.6 \mathrm{~K}$ (with a mean of $-1.9 \mathrm{~K}$ ). Neutral-core events exhibit a much steeper temperature anomaly gradient approaching the tropopause and larger anomalous heating aloft (Fig. 13). The sample of warm-core depressions is too small to draw any significant conclusions. The neutralcore-minus-cold-core PV composite (not shown) has lower tropopause height above cold-core depressions and higher PV in the flanks near the surface; the centers of each type appear very similar. Also not shown graphically is the comparison of surface rainfall rates between coldand neutral-core events; these are given in Table 1. The greater rainfall rates, and the slightly larger area of influence of neutral-core events, should be expected upon inspection of the temperature profiles, which show that neutral-core events exhibit a warmer core aloft, indicating stronger latent heating.

\section{f. CAPE and tephigram analysis}

Variables relating to convection are important because they provide an insight into how thermal energy is distributed and used within a system.
Figure 14 shows that the maximum CAPE is found approximately $5^{\circ}$ ahead of the center, reaching a peak value of $2050 \mathrm{~J} \mathrm{~kg}^{-1}$. The minimum CIN is found near the center, with a value of $-1.2 \mathrm{~J} \mathrm{~kg}^{-1}$ but increasing exponentially ahead of the depression. There are two competing effects at the center: a strong positive moisture anomaly (reducing the CIN; i.e., less negative) and a steeper temperature anomaly gradient (increasing the (IN); however, the moisture anomaly has a much stronger effect and dominates the CIN.

Figure 15 shows soundings through the center (single grid point) in the composite depression and two subsets. The full composite (Fig. 15a) has evidence of strong ascent through the lower and middle troposphere, and we can deduce large CAPE by considering the saturated pseudoadiabat coinciding with Normand's point (approximately $950 \mathrm{hPa}$ ). Extrapolation of this adiabat to the upper troposphere suggests a level of neutral buoyancy at approximately $120 \mathrm{hPa}$. We also split the composite into two pairs of subsets: day-night (Fig. 15b) and land-ocean (Fig. 15c). The day-night tephigram indicates that the daytime sounding is slightly warmer and drier throughout its height, though the more substantial temperature and moisture differences in the boundary 


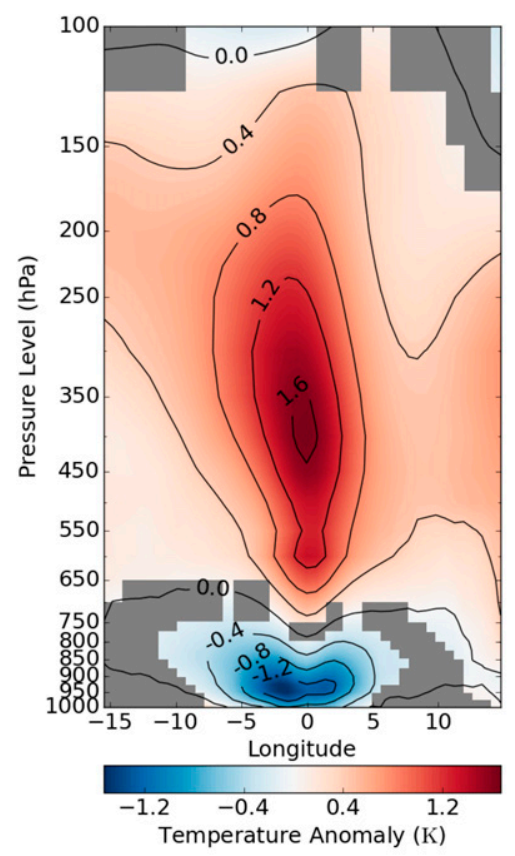

(a) Temperature

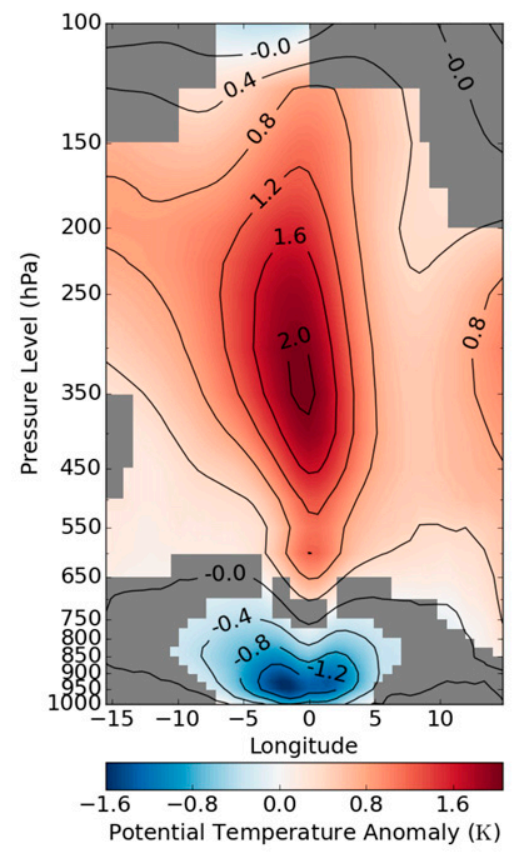

(b) Potential temperature

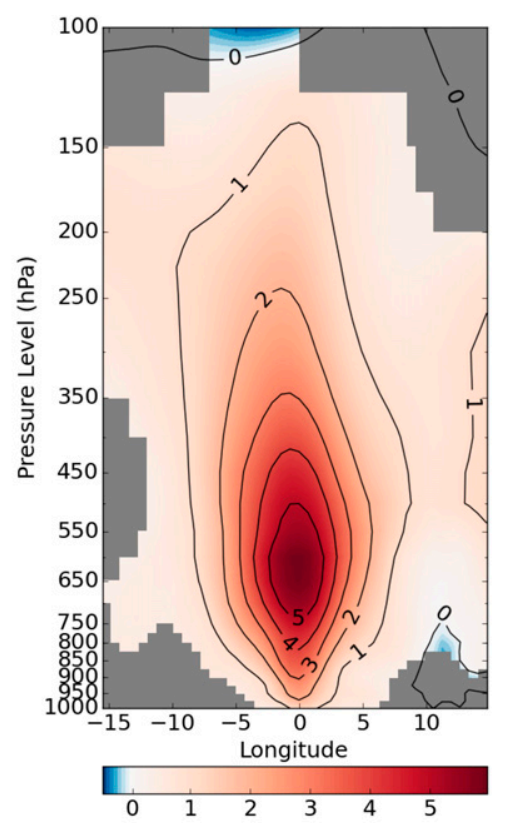

Eq. Potential Temperature Anomaly (K)

(c) Equivalent potential temperature

FIG. 12. Vertical structure of (a) temperature (K), (b) potential temperature anomaly (K), and (c) equivalent potential temperature anomaly (K). Colors are grayed out where the profiles are not significantly different from the climatology at the $95 \%$ significance level.

layer engender high CAPE and very small CIN during nighttime (lower temperature but same dewpoint raises the relative humidity). The land-ocean contrast shows that, particularly in the midtroposphere, there is generally a cooler, moister environment over the ocean with lower CAPE and greater CIN.

Calculable products from these tephigrams and several others (not shown) are given in Table 2. Important results are larger CAPE and reduced (less negative) CIN in the final day (almost always over land) when compared to the first day (almost always over ocean) and larger CAPE in neutral-core events than cold-core events [because, despite the shorter distance (in pressure units) between the level of free convection and the level of neutral buoyancy, the parcel temperature is comparatively much higher-compare Fig. 13a and Fig. 13b]. In neutral-core depressions CIN is nearly 3 times greater than in cold-core depressions owing to higher surface temperature and resultant lower relative humidity. This is a significant difference because there is very low variance in CIN at the center of the composite (not shown).

In general, the level of neutral buoyancy is near the top of the cloud deck (cf. Fig. 8c), and any difference is likely accountable to entrainment of surrounding cool, dry air. The lifted condensation level is comparable to the bottom of the cloud deck.
We examine variations in profiles according to the diurnal cycle or surface type in the next section.

\section{g. Summary of composite vertical structure}

Figure 16 shows some key features of the vertical structure presented throughout this section. In particular, we note the generally asymmetric structure: a westward axial tilt in many fields and an intensification of the lower-tropospheric winds on the Himalayan side of the vortex.

\section{Variability within the composite}

Although most of our composite diagnostics have been presented with a test of statistical significance, we also discuss the stability of the composite, first using standard deviation of the entire composite, and second by breaking the composite down and contrasting land, sea, and transitional (coastal) phases. The latter is particularly important as the conditions surrounding a depression spinning up in the Bay of Bengal are very different to those as it decays over north India. We also consider the diurnal contrast within depressions.

\section{a. Standard deviation}

Most fields are highly homoscedastic, with a standard deviation far smaller than the anomaly to the climatology; 


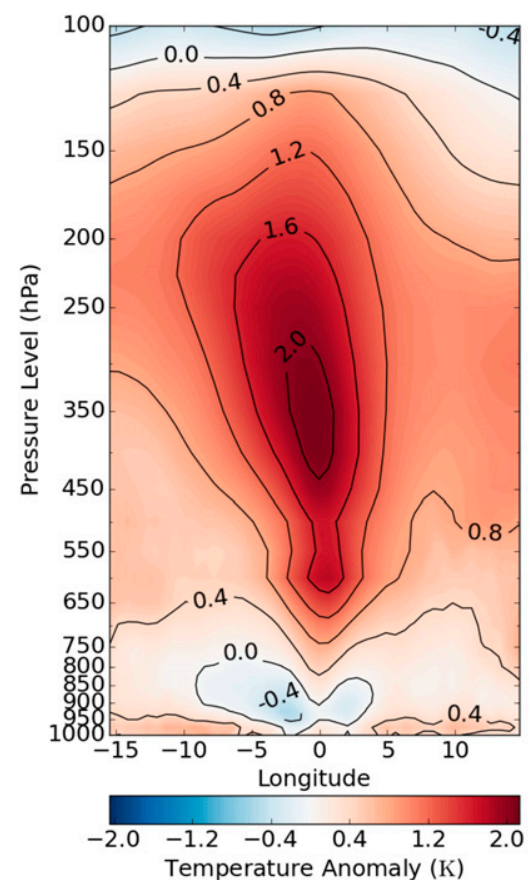

(a) Neutral-core (28 events)

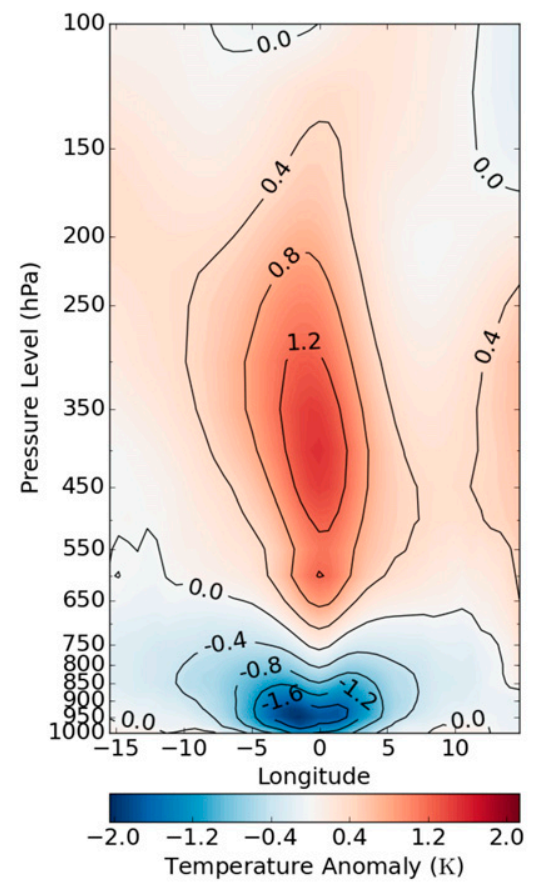

(b) Cold-core (76 events)

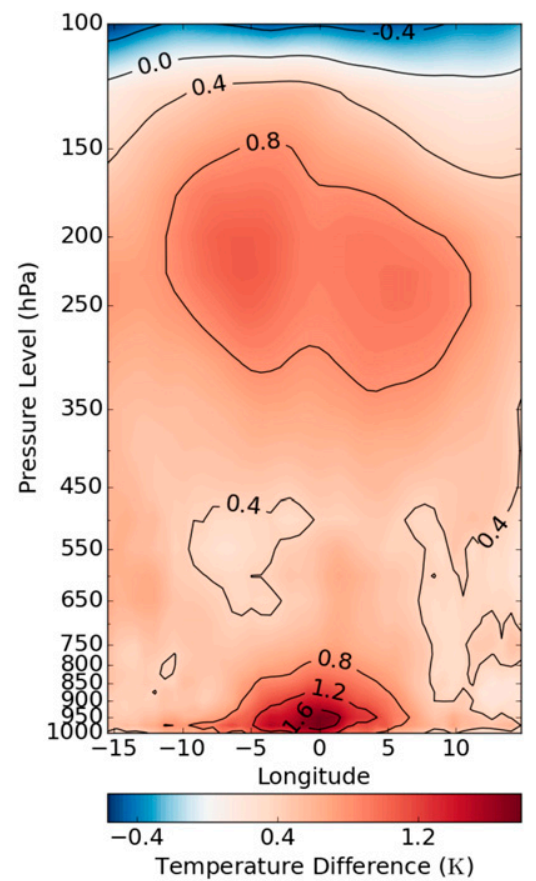

(c) Neutral- minus cold-core

FIG. 13. Vertical structure of the temperature $(\mathrm{K})$ as an anomaly to the boreal summer mean for a composite depression with both main core categories, and their difference: (a) neutral core, (b) cold core, and (c) their difference. In (a) and (b), colors are grayed out where the subsets do not significantly differ from the full composite temperature profile at the $95 \%$ confidence level, ascertained by the bootstrapping method; in (c), colors are grayed out where the difference does not significantly differ from zero at the $95 \%$ confidence level using the bootstrapping difference method on the full composite temperature profile.

hence, the large areas of significance in the horizontal and vertical cross sections presented above. Variance invariably reaches a maximum in the deep flanks of the composite, where influence from the major processes within the depression is very low, and the effects of varying environment, composite rotation, and different depression sizes start to become significant.

\section{b. Variability over the lifetime}

If we can understand how the structure of depressions transforms over time, we can better represent their processes in models and better predict their durations and trajectories. Almost all depressions form over the ocean and eventually die over land, so there is likely to be some correlation between young (old) depressions and ocean (land) depressions: the latter is discussed in detail in the next section.

Figure 17a shows how the central pressure, wind, and vorticity extrema vary as a function of depression age. The variables for each depression were interpolated onto a lifetime-percentage array, rather than using an absolute time scale because depressions have considerably variable durations (see Fig. 17b). All variables demonstrate a midlife extremum: central pressure (represented as geopotential height anomaly) reaches a minimum before wind speed and relative vorticity, both of which have maxima around $60 \%$ before decaying significantly and rapidly during the dissipation phase of the depression. If we compare first-day and final-day PV composites (not shown, but see Fig. 9a), the most immediate difference is the extent of the upper anticyclone, which has a larger (more positive) PV in the flanks in the final day when compared to the first one. Differences near the surface extend to approximately $550 \mathrm{hPa}$ and feature generally lower (less positive) PV in the center and higher PV in the flanks on the final day.

TABLE 1. Some data showing rainfall rates $\left(\mathrm{mm} \mathrm{day}^{-1}\right)$ of selected percentiles for cold- and neutral-core depressions over the domain used in, for example, Fig. 14.

\begin{tabular}{ccc}
\hline \hline Percentile & Cold core $\left(\mathrm{mm} \mathrm{day}^{-1}\right)$ & Neutral core $\left(\mathrm{mm} \mathrm{day}^{-1}\right)$ \\
\hline 50 & $\sim 0$ & $\sim 0$ \\
75 & 1.75 & 3.47 \\
90 & 22.9 & 29.0 \\
95 & 50.4 & 60.2 \\
99 & 141 & 165 \\
99.9 & 305 & 339 \\
\hline
\end{tabular}




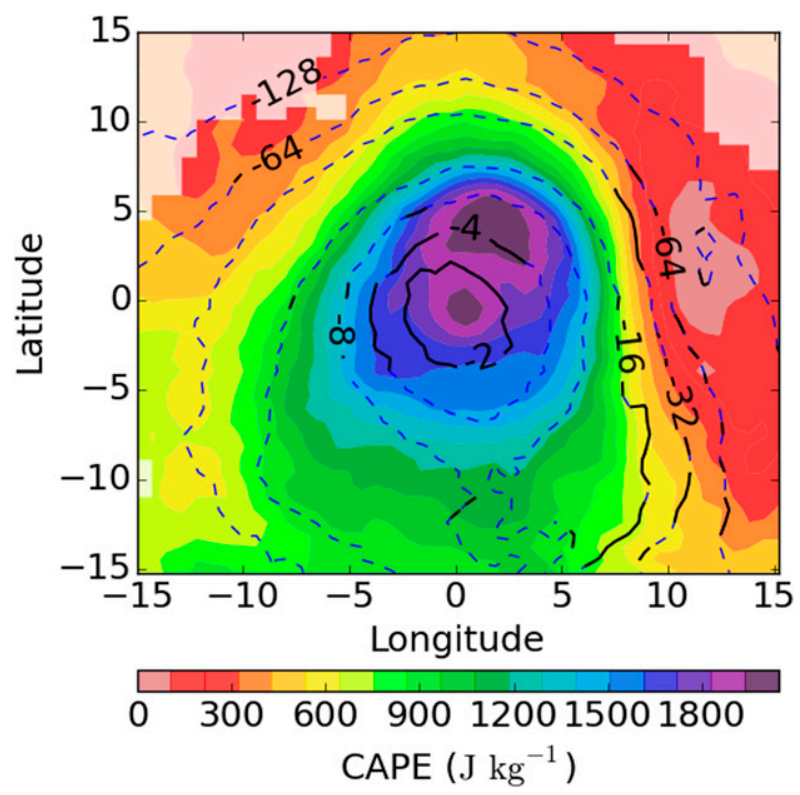

FIG. 14. Horizontal composite of CAPE $\left(\mathrm{J} \mathrm{kg}^{-1}\right)$ in colored contours and CIN $\left(\mathrm{J} \mathrm{kg}^{-1}\right)$ in line contours. Significance as in Fig. 5.

A histogram giving the lifetimes of each individual depression tracked is shown in Fig. 17b. It shows the shortest-lived depressions last approximately a day: this is the threshold for the IMD and our tracking software, but depressions can have lifetimes as long as nearly 10 days, with a mode of just over 3 days. This distribution is the reason information in Fig. 17a is presented as it is. Several well-known probability distributions were fitted to the data in Fig. 17b, with the generalized logistic distribution (shown) having the smallest meansquare error.

We also find that there is no significant relationship between depression frequency and time of year and that the frequency has little effect on all-India rainfall; Raghavan (1967), Dhar and Rakhecha (1976), and Krishnamurthy and Ajayamohan (2010) showed that this is because low pressure systems result in excess rainfall in some areas but deficient rainfall in others. The correlation coefficient between trough rainfall and the depression frequency for the relevant period (19982013) is 0.77 .

\section{c. Coastal transitions and the land-sea contrast}

Land-atmosphere and ocean-atmosphere interactions can differ from each other considerably, so we expect monsoon depressions (which as we have seen, are fairly dependent on surface interactions) to differ considerably also. To explore the effect of surface type (land, coast, ocean) of monsoon depressions, we first define a coastal transition region, sufficiently wide to span the typical horizontal scale of the core of a passing depression, but not so large as to prejudice the sample sizes of land or ocean composites. A threshold of $\pm 200 \mathrm{~km}$ either side of the coast was chosen, providing a sample of 680,687 , and 159 6-hourly depression time steps for land, coastal, and ocean areas, respectively, with the advantage that many fields (e.g., potential vorticity, geopotential height anomaly, vertical wind speed) have values of less than half their central extrema at this radius. The location of the center is used to define the entire depression.

For specific humidity (not shown), the difference between the three partial composites is again significantly less than the standard deviation (by a factor of 4) across the full composite, even though this variable is so dependent on surface composition. There is, however, a "tightening up" in the lower levels, where the horizontal extent of the central maximum at each height is reduced at each progressive stage. This is a common theme throughout the comparison of ocean-land compositesthe magnitude of any central extremum differs insignificantly if at all, but in many fields we observe an increasing confinement to the central axis, resulting in a steeper horizontal gradient. The same analysis with potential vorticity (not shown) reveals little significant variation across the surface types.

There is little difference between the three partial composites for equivalent potential temperature anomaly (Fig. 18): the maximum is highest in the land-based composite but does not differ much from either the ocean- or coast-based composites. All three demonstrate a warm core at approximately $650 \mathrm{hPa}$.

CAPE around the center of the land-based composite is much higher than its ocean-based counterpart (Table 2), but this maximum has a much smaller extent ( $\sim 6^{\circ}$ wide as opposed to $\sim 20^{\circ}$ wide; not shown).

We also separately composited points according to their instantaneous location, resulting in "purely oceanic" and "purely land-based" composites. Figure 19 shows the wind structure of such a composite: average sample sizes are 465 time steps for ocean and 1060 for land in this and subsequent composites. The nearsurface winds around the core are weaker over the land, partly as a result of friction, and partly as a result of the loss of warm water vapor as an energy source. The strong winds also become a lot more constrained to the center as the depression passes over land and weakens. The difference between the two in Fig. 19c reflects the weakening and constriction of the winds near the surface. The tropospheric winds round the core strengthen more over land to the relative east than to the relative west, possibly owing to orographic channeling by the Himalayas.

Further ocean-minus-land vertical composites (as Fig. 19c) are shown in Fig. 20. Specific humidity shows little contrast between the two in the lower levels, with 


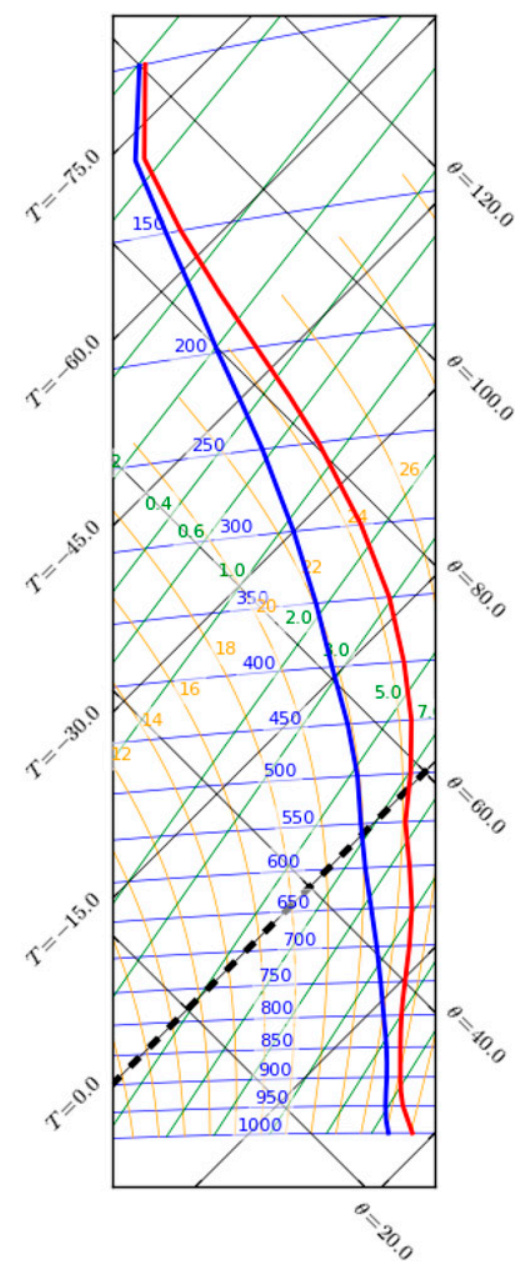

(a) Full composite

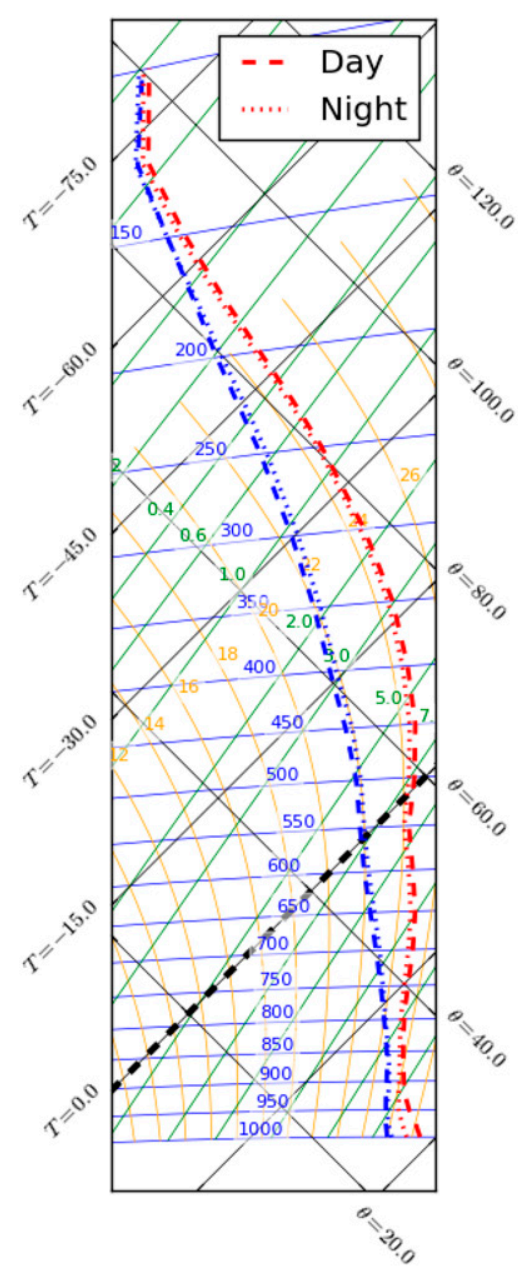

(b) Day/night split

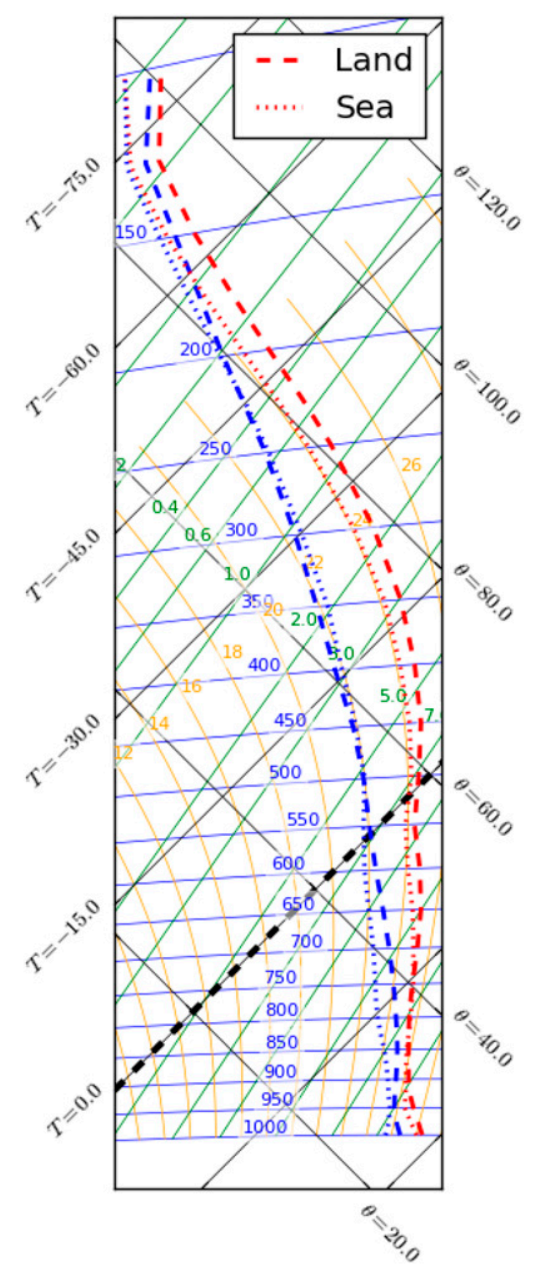

(c) Land/sea split

FIG. 15. Tephigrams of simulated soundings going through the center of the composite depression and selected subsets. Temperature in red; dewpoint temperature in blue.

the only significant difference being the drier flanks above the ocean at a radius of $\sim 10^{\circ}$. In the middle and upper troposphere, however, the ocean composite has considerably more moisture, particularly outside the center. The difference in relative vorticity (Fig. 20b) shows that the composite is less constrained to the center over the ocean and that the vortical core penetrates nearer to the ocean surface than to the land, a plausible result of orographic friction. So the depression is larger and more intense over water than land, although these differences are fairly small when compared to the mean structure. The tropical summer atmosphere is generally cooler over the ocean than land, so it is important to see how the depression organizes this difference, shown in Fig. 20c. As expected, it is cooler throughout, although the deep latent heating from increased precipitation removes much of the difference at and near the center; in the flanks, the difference is of order $1-2 \mathrm{~K}$, and explains much of the counterintuitive structure of the difference in specific humidity.

Surface latent heat flux (not shown) is substantially larger over the ocean (maximum 185, average $150 \mathrm{~W} \mathrm{~m}^{-2}$ ) than over land (maximum 95, average $65 \mathrm{~W} \mathrm{~m}^{-2}$ ): as expected, the maxima are collocated with lowertropospheric wind speed and they have local minima at the center. Surface sensible heat flux (not shown) also has central minima over both land and ocean, following the surface temperature structure. As in the full composite, there exists a boundary layer height minimum of equal magnitude $(\sim 500 \mathrm{~m})$ over both the land and ocean composite centers, rising to the respective climatological values within several hundred kilometers. 
TABLE 2. Some tephigram data for different composites. Abbreviations: lifted condensation level (LCL), level of free convection (LFC), level of neutral buoyancy (LNB), convective available potential energy (CAPE), and convective inhibition (CIN). These values were calculated directly from the relevant composite.

\begin{tabular}{|c|c|c|c|c|c|}
\hline & $\mathrm{LCL}(\mathrm{hPa})$ & LFC (hPa) & LNB (hPa) & CAPE $\left(\mathrm{J} \mathrm{kg}^{-1}\right)$ & $\overline{\mathrm{CIN}}\left(\mathrm{J} \mathrm{kg}^{-1}\right)$ \\
\hline Full & 972.9 & 938.0 & 117.8 & 2007 & -1.29 \\
\hline Neutral core & 963.7 & 913.1 & 112.8 & 2174 & -3.03 \\
\hline Cold core & 976.9 & 948.5 & 119.9 & 1940 & -1.20 \\
\hline First $24 \mathrm{~h}$ & 967.8 & 915.7 & 123.1 & 1693 & -2.24 \\
\hline Final $24 \mathrm{~h}$ & 970.0 & 931.3 & 117.4 & 2139 & -1.81 \\
\hline Land & 975.0 & 944.0 & 113.8 & 2373 & -1.26 \\
\hline Coast & 972.2 & 933.6 & 121.2 & 1788 & -1.70 \\
\hline Ocean & 964.8 & 892.6 & 118.6 & 1798 & -2.80 \\
\hline Upper-quartile intensity & 974.8 & 943.8 & 111.9 & 2161 & -1.51 \\
\hline Lower-quartile intensity & 971.8 & 929.3 & 125.2 & 1792 & -1.85 \\
\hline Day & 962.7 & 920.3 & 119.2 & 1900 & -3.30 \\
\hline Night & 983.1 & 961.3 & 117.0 & 2109 & -0.43 \\
\hline
\end{tabular}

\section{d. Diurnal cycle}

We have already noted contrasts between composite depression structure in day-night conditions. As ERAInterim data are released in 6-hourly time steps starting with 0000 UTC, the night composite was constructed from 1800 and 0000 UTC (2330 and 0530 Indian standard time), and the day composite from 0600 and 1200 UTC. We examined the day-night difference in selected composite variables (Fig. 21); only a few of many fields examined showed significant differences away from the center. Figure 21a shows that the day composite is almost ubiquitously $0.2 \mathrm{~K}$ hotter, with the increase rising to over $1.3 \mathrm{~K}$ in the lower troposphere, this maximum being due to strong thermal interaction between the atmospheric boundary layer and the surface (see also section 4f). Figure 21b shows that (as in Fig. 15b) the daytime depression is also drier throughout in terms of relative humidity. Figure 21c shows that there is a nearly universal reduction in cloud cover by day, particularly in the low-level cloud at the center.

\section{The influence of large-scale forcing}

We now consider whether organized modes of variability such as intraseasonal and interannual modes connected to the monsoon can influence the structure of monsoon depressions.

\section{a. El Niño-Southern Oscillation}

El Niño-Southern Oscillation (ENSO) is responsible for a significant fraction of the interannual variability within the monsoon system, affecting precipitation by as much as $20 \%$ (Webster et al. 1998). It is therefore plausible that synoptic-scale systems (such as depressions) within the monsoon might also be significantly affected by ENSO. We define an
ENSO event as a contiguous seven month period with a Niño-3.4 region index of greater than $0.5 \mathrm{~K}$. Such an episode is then linked to the monsoon season that precedes it.

While warm-core tropical cyclone activity is enhanced over the Indian Ocean during La Niña and suppressed

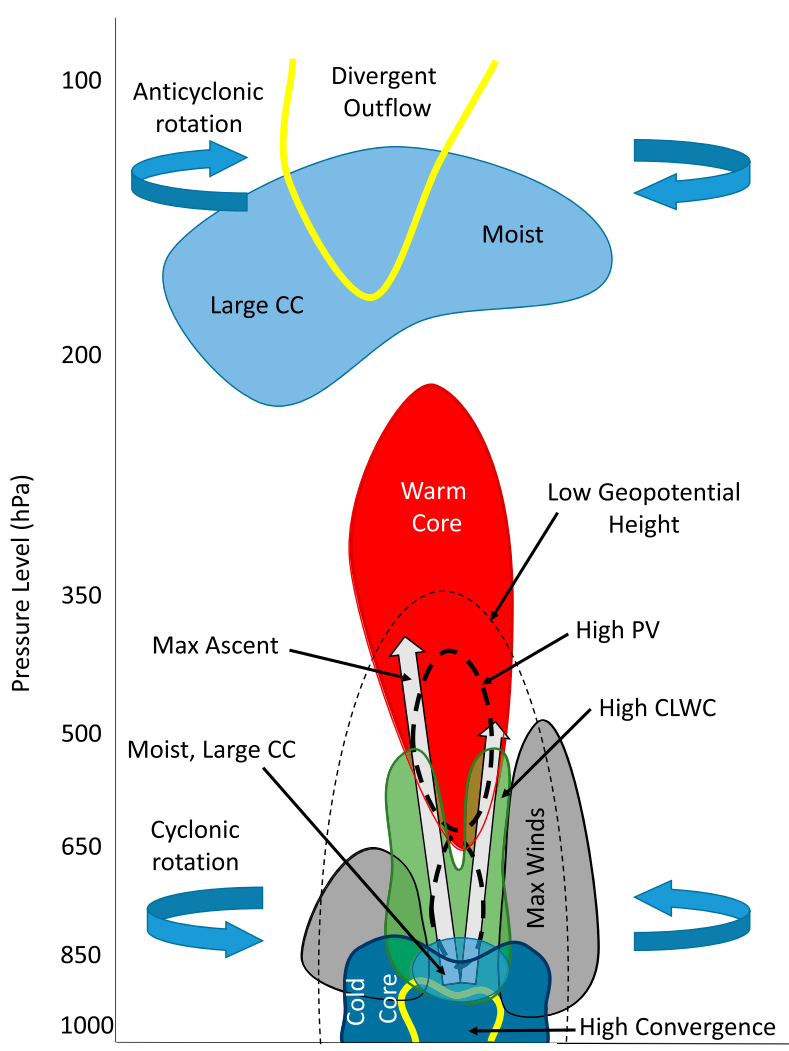

FIG. 16. Schematic of the composite monsoon depression: $\mathrm{CC}=$ cloud cover; $\mathrm{CLWC}=$ cloud liquid water content; and PV = potential vorticity. 


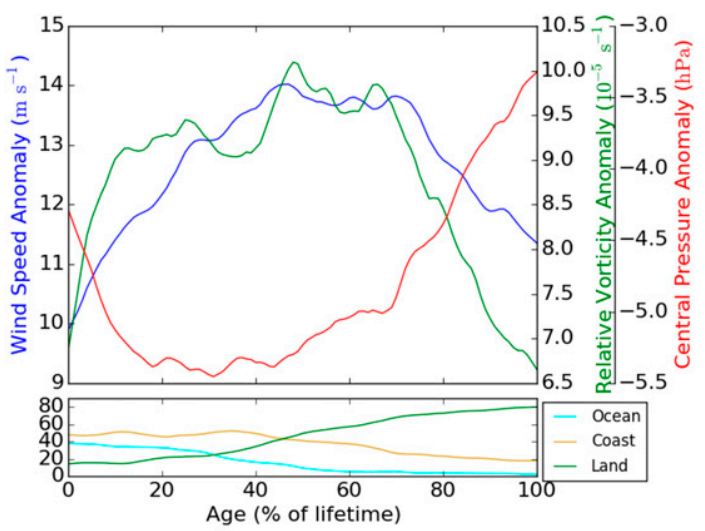

(a) Evolution of some selected variables

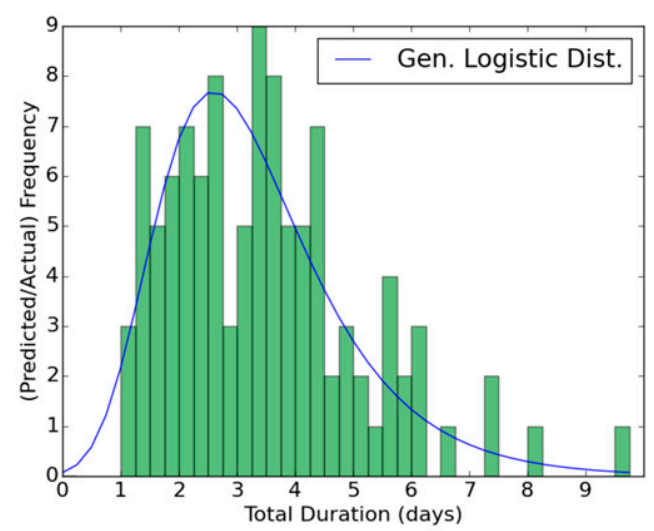

(b) Histogram of durations

FIG. 17. (a) Surface pressure anomaly at center (hPa), maximum $850-\mathrm{hPa}$ wind speed anomaly $\left(\mathrm{m} \mathrm{s}^{-1}\right)$, and 850-hPa central relative vorticity anomaly $\left(10^{-5} \mathrm{~s}^{-1}\right)$ of the composite depression as a function of percentage of lifetime duration, with respective percentage of systems over land, coast (defined as within $200 \mathrm{~km}$ of coastline), and sea shown underneath, anomalies are relative to a 21-day running mean. (b) Histogram of depression durations, with the generalized logistic function fitted. The mean depression duration is 3.3 days, with a standard deviation of 1.6 days.

during El Niño (e.g., Bell et al. 2014), we find (Table 3) that the reverse is true for cold-core depressions, with approximately $16 \%$ more activity during El Niño years than La Niña [cf. $12 \%$ in the Hurley and Boos (2015) dataset]. Krishnamurthy and Ajayamohan (2010) studied monsoon low pressure systems (rather than specifically depressions) and found a slight increase in low pressure system (LPS) days during La Niña.

Figure 22a shows the El Niño-minus-La Niña rainfall composite for depressions in La Niña years during the TRMM dataset period. The overall rainfall rate, away from the center, in La Niña depressions is considerably

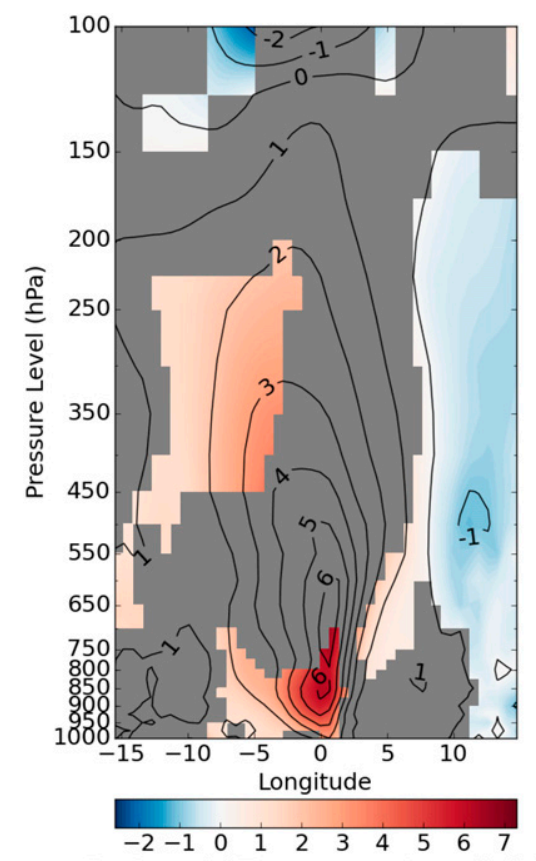

Eq. Potential Temperature Anomaly $(K)$

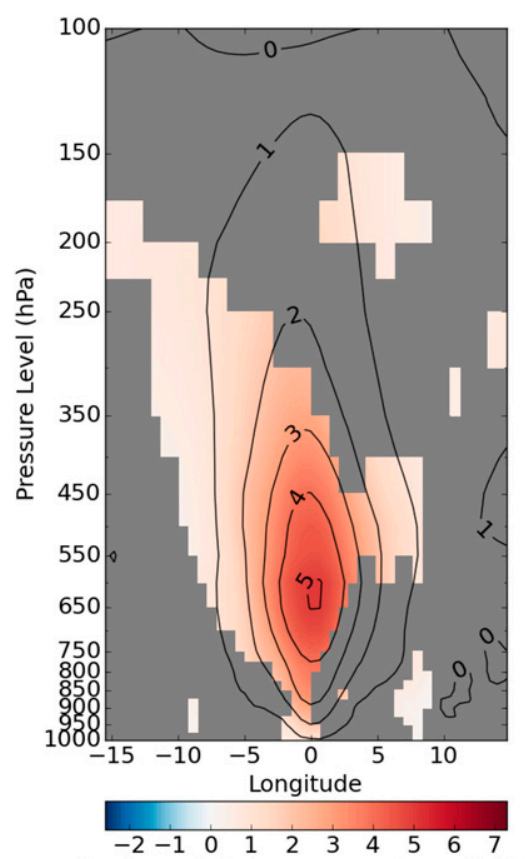

Eq. Potential Temperature Anomaly $(K)$

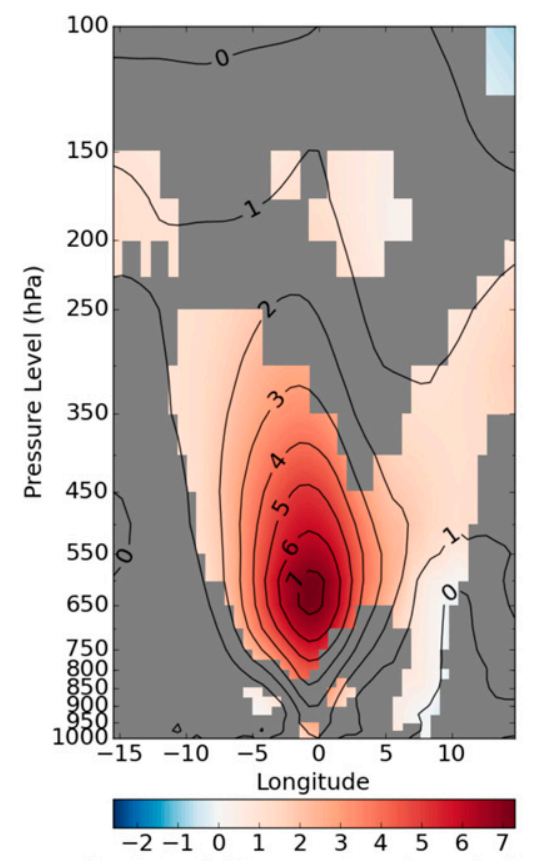

Eq. Potential Temperature Anomaly $(K)$

(a) Ocean

(c) Land

FIG. 18. Vertical structure of equivalent potential temperature (K): (a) ocean, (b) coastal, and (c) land composites. Colors are grayed out where the subset is not significantly different from the full composite at the $95 \%$ confidence level. 


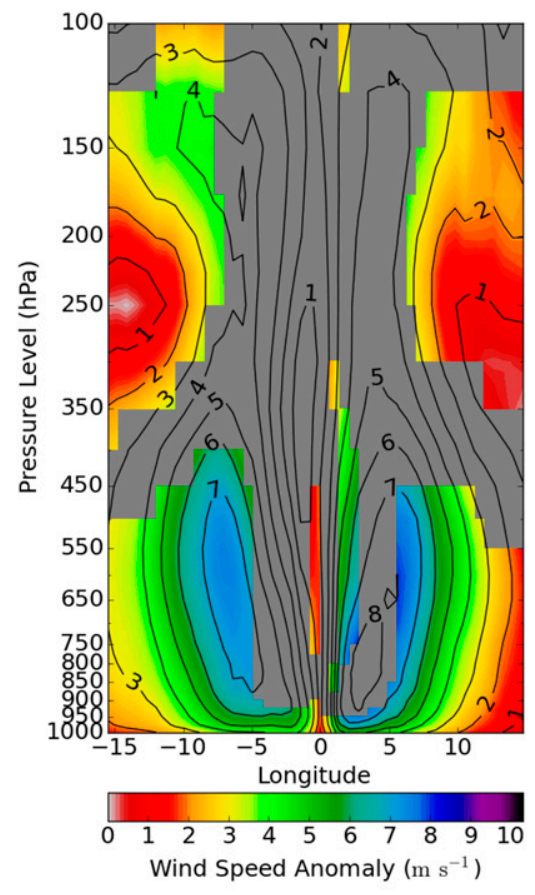

(a) Ocean

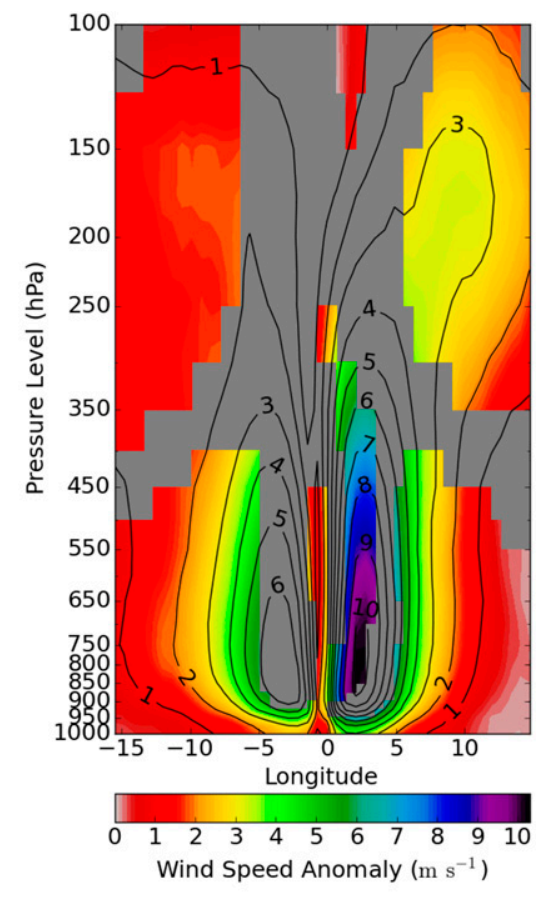

(b) Land

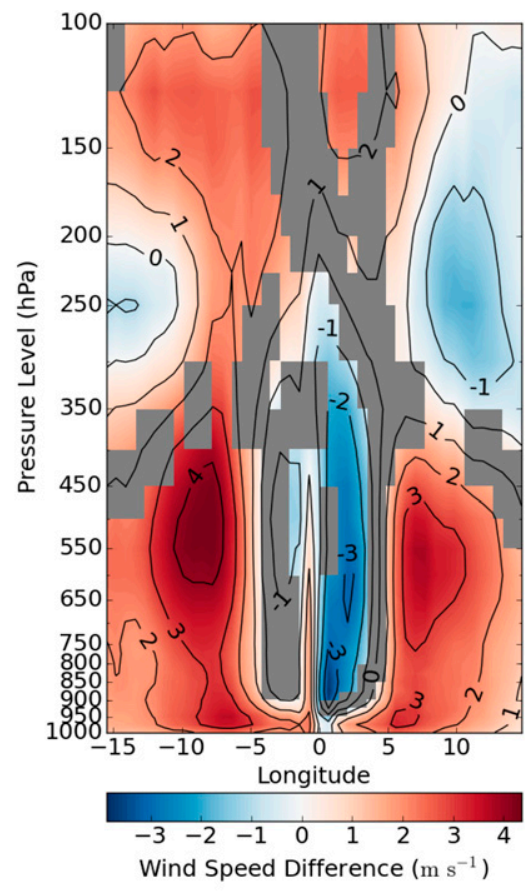

(c) Ocean-minus-land

FIG. 19. Vertical structure of wind speed anomaly $\left(\mathrm{m} \mathrm{s}^{-1}\right.$ ) for purely (a) oceanic and (b) land-based composite depressions; (c) their difference. Significance as in Fig. 13.

greater than that of El Niño years; this agrees with the strong correlation between drought-flood years and El Niño-La Niña years, respectively (e.g., Rasmusson and Carpenter 1983; Ropelewski and Halpert 1987; Webster and Yang 1992). However, there is evidence of a stronger, more moist core to the El Niño depressions.

ERA-Interim reanalysis data in time steps of $6 \mathrm{~h}$ show a total of 381.5 depression days spread among the 106 depressions (Table 3). For El Niño years, there were 7 and 29 neutral- and cold-core depressions, respectively, whereas for La Niña years, the count was 10 and 23 (with 11 and 22 for neutral years). So, for neutral and La Niña years, cold-core depressions were only a little over twice as likely as neutral-core counterparts; whereas for El Niño years, they were over 4 times as numerous here. This could be in part due to El Niño depressions being drier (Fig. 23c), allowing greater reduction in temperature via latent heat of evaporation. However, the sample sizes are small, so the results may not be significant.

Figures 23a-c show the vertical structure for several variables in the El Niño-minus-La Niña composite. The structure of the geopotential height (see Fig. 23a) is quite different. We see the surface is almost entirely at a higher geopotential height (i.e., higher pressure) for the El Niño composite compared to the La Niña one. With altitude this falls, with a 0 -m isohypse passing over the center at approximately $420 \mathrm{hPa}$. Therefore, an El Niño depression is typically colder than a La Niña depression from the midtroposphere upward (Fig. 23b), since pressure falls off more rapidly with height. This is probably because weaker mean-state convection in El Niño depressions releases less latent heat aloft. The differences in structure of relative vorticity (not shown) indicate the core is considerably less cyclonic in El Niño depressions, remaining so (with reducing intensity) up to the tropopause. This comparatively less vigorous core is surrounded by zones of higher relative vorticity that also persist and spread out aloft, indicating that these depressions have a less tightly wound center but stronger rotation in the flanks.

As we might expect from Fig. 22a, the La Niña composite (Fig. 23c) is generally relatively moister, especially in the midtroposphere, with some closed $-6 \times$ $10^{-4} \mathrm{~kg} \mathrm{~kg}^{-2}$ isohumes around $600 \mathrm{hPa}$ in El Niño relative to La Niña. There is also a surface gradient, with the El Niño composite possessing comparatively drier air in the relative west. A more detailed analysis of the ENSO differences is beyond the scope of this study.

\section{b. The Indian Ocean dipole}

The Indian Ocean dipole (IOD) was first identified by Saji et al. (1999) and we represent it by their dipole mode index (DMI), defined as the difference in SST 


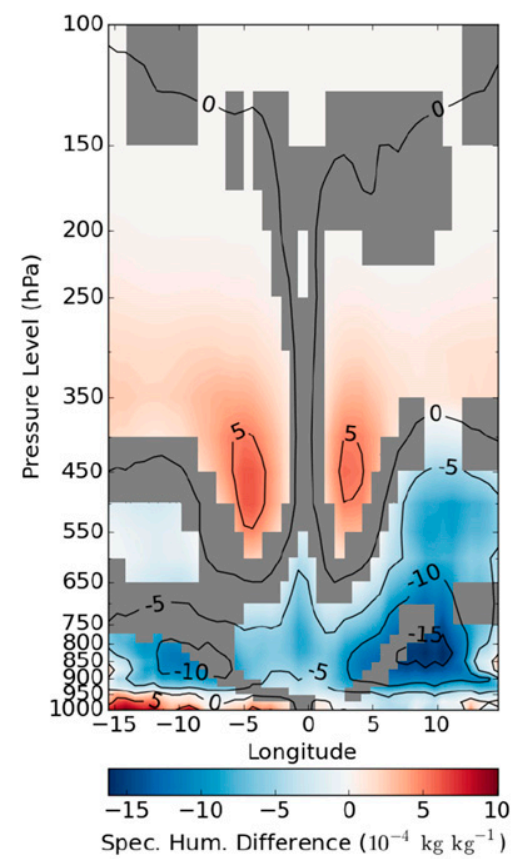

(a) Specific humidity

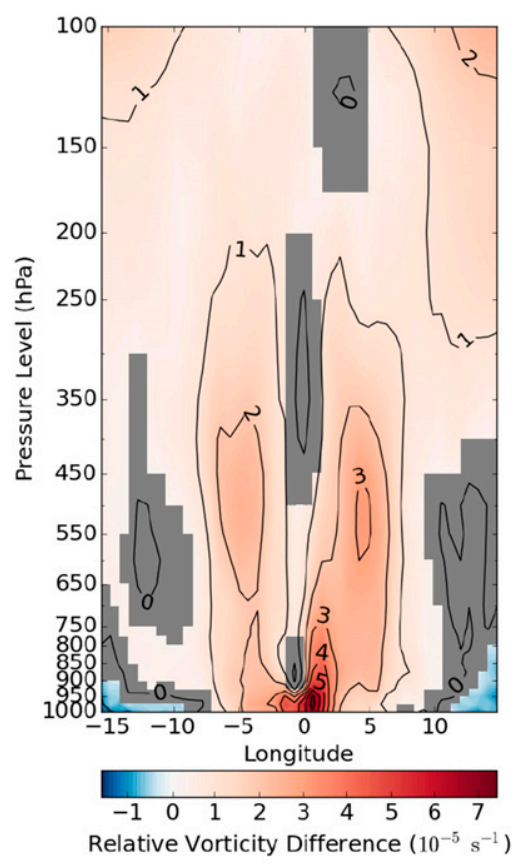

(b) Relative vorticity

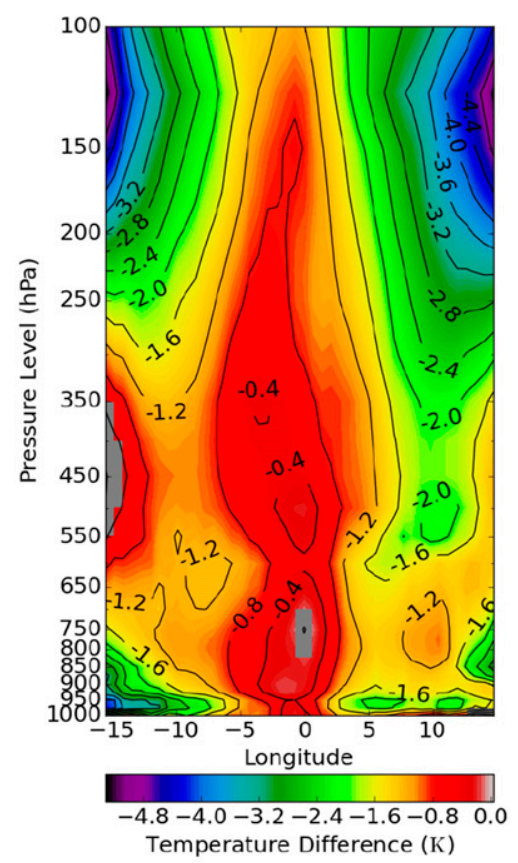

(c) Temperature

FIG. 20. Vertical structure of the ocean-minus-land composite (as in Fig. 19c) for specific humidity $\left(10^{-4} \mathrm{~kg} \mathrm{~kg}^{-1}\right)$, relative vorticity $\left(10^{-5} \mathrm{~s}^{-1}\right)$, and temperature (K). Significance as in Fig. 13c.

anomalies between two boxes in the west $\left(10^{\circ} \mathrm{S}-10^{\circ} \mathrm{N}\right.$, $\left.50^{\circ}-70^{\circ} \mathrm{E}\right)$ and southeast $\left(10^{\circ} \mathrm{S}-0^{\circ}, 90^{\circ}-110^{\circ} \mathrm{E}\right)$ Indian Ocean. Values greater than 0.5 (less than -0.5 ) are named positive (negative) IOD events. Krishnan et al. (2011) considered the positive IOD event of 2006 and its contemporaneous depressions, showing that there was a positive feedback system that contributed to the longevity of depressions. They subsequently generalized their study to a climatology and found that positive IOD events added approximately $12 \%$ to the lifetime of depressions. Here, we briefly explore (see Figs. 23d-f) the difference in structure between monsoon depressions in positive and negative IOD environments. The state of the IOD has a much lesser impact on depressions than does ENSO.

The difference in geopotential height is shown in Fig. $23 \mathrm{~d}$ and indicates that depressions associated with positive IOD events are slightly weaker and larger. This is corroborated by the temperature structure (Fig. 23e), which shows a weakening of the warm core aloft. This may be connected to the cooling of the ocean at the head of the Bay of Bengal, where most depressions originate (Fig. 24a), resulting in less moisture being available from evaporation for early intensification processes. However, as Krishnan et al. (2011) showed, positive IOD events result in greater cross-equatorial moisture flux and an increase in the meridional shear of the zonal wind (resulting in greater barotropic instability), which supports the depression in its transit across the trough and stalls the dissipation. The difference in specific humidity between positive and negative IOD events (Fig. 23f) displays little coherent structure and is not significantly different from zero almost anywhere.

The state of the subcontinent in both $850-\mathrm{hPa}$ winds and surface temperature is given for IOD positiveminus-negative and ENSO positive-minus-negative depression days in Figs. 24a and 24b, respectively. The well-defined IOD structure in SST induces an anomalous north-south land surface temperature gradient and a slight strengthening of the monsoonal winds. In contrast, the ENSO difference pattern shows a slight weakening of the monsoonal winds and a warmer surface owing to deficient rainfall. To conclude, El Niño conditions may produce more depressions than La Niña, but they are weaker, whereas the IOD makes no significant difference to the structure of depressions. The influence of the IOD on surface rainfall (not shown) is also slight, but in agreement with the small difference in temperature: the slight drop in temperature throughout the profile of the IOD positive composite is accompanied by a small reduction in precipitation. The maxima in both composites are still found in the relative southwest sector, with an IOD 


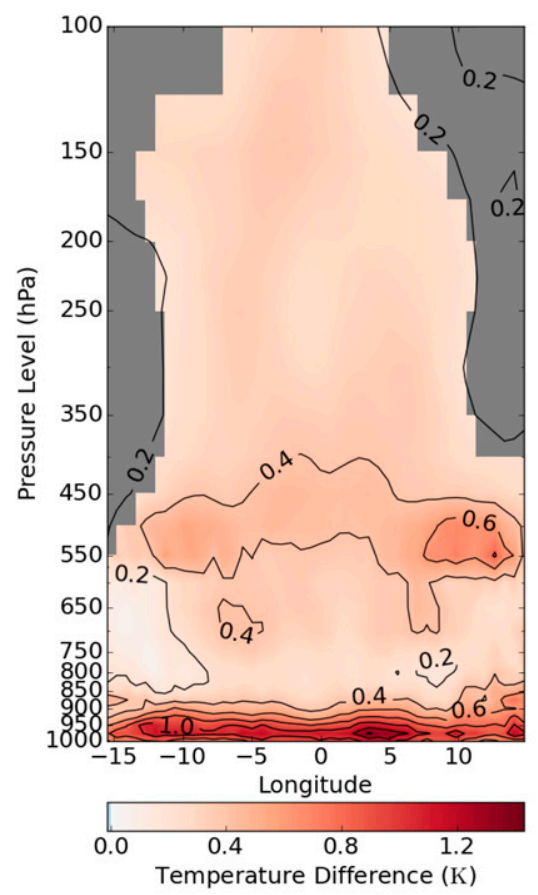

(a) Temperature

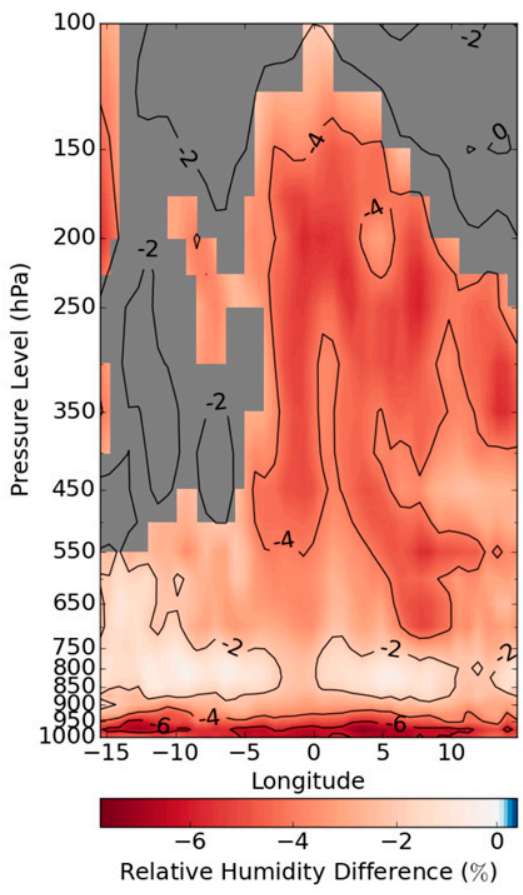

(b) Relative humidity

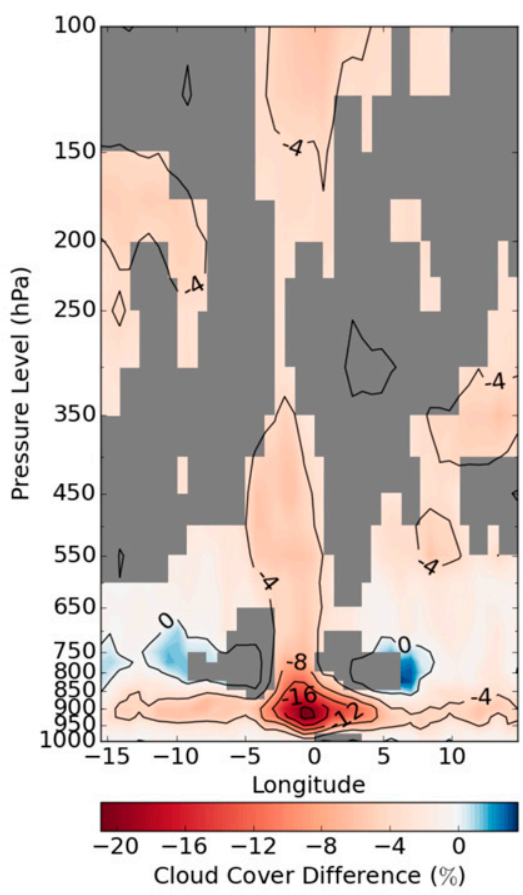

(c) Cloud cover

FIG. 21. Diurnal variation as represented by a day-minus-night composite for (a) temperature (K), (b) relative humidity (\%), and (c) cloud cover (\%). Significance as in Fig. 13c.

positive maximum of $50 \mathrm{~mm} \mathrm{~h}^{-1}$ and an IOD negative maximum of $56 \mathrm{~mm} \mathrm{~h}^{-1}$.

\section{c. Active and break phases}

Active (enhanced rainfall) and break (suppressed rainfall) phases of the monsoon significantly affect both spatial rainfall distribution and depression frequency (Krishnamurthy and Shukla 2007), with far more depression days during active periods. We can combine ENSO-based prevalence with active-break prevalence (see Table 3). We used data on active and break spells from Pai et al. (2014), requiring constriction of the dataset to July and August 1979-2010 (leaving 51\% of samples).

Because of the relative sparsity of depressions coinciding with breaks (Krishnamurthy and Shukla 2007, also Table 3), meaningful statistics of break depressions were unrealizable. Therefore, we compare depression composites in active and neutral spells (see Figs. 23g-i). Active-spell lower-tropospheric geopotential height (Fig. 23g) is much lower pressure in the center, with a much steeper vertical gradient, suggesting that depressions intensify under active conditions.

The maximum magnitude of the temperature difference is little greater than $0.5 \mathrm{~K}$ (Fig. 23h), but active depressions clearly exhibit a slightly colder core at the surface and a warmer upper troposphere because of the greater release of latent heat through the stronger convection. This is an amplification of the structure seen in Fig. 12a and further implies a strengthening of depressions under active monsoon conditions.

The active composite has a much more cyclonic core, flanked on either side by areas of considerable relative anticyclonicity, and with a weaker corresponding anticyclone. The composite active depression is considerably wetter in the midlevels $(750-500 \mathrm{hPa})$ as expected (Fig. 23i). This difference composite also exhibits a slight relative east-west gradient at the surface (as with El Niño-La Niña): wetter in the west and drier in the east.

The average relative vorticity (again, as an anomaly to the climatology) over South Asia for depression days is illustrated in Fig. 25a. The most immediately apparent

TABLE 3. Distribution of depression days with respect to ENSO and active-break cycles.

\begin{tabular}{lllll}
\hline & Active & Neutral & Break & Total \\
\hline El Niño & 39 & 90.75 & 0 & 129.75 \\
Neutral & 20.25 & 97.25 & 1.75 & 119.25 \\
La Niña & 27.25 & 104 & 1.25 & 132.5 \\
Total & 86.5 & 292 & 3 & 381.5 \\
\hline
\end{tabular}




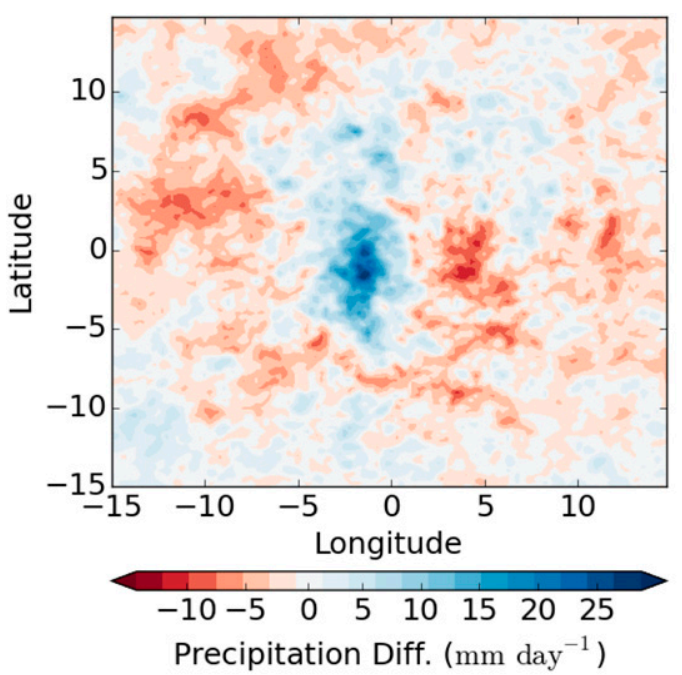

(a) El Niño-minus-La Niña

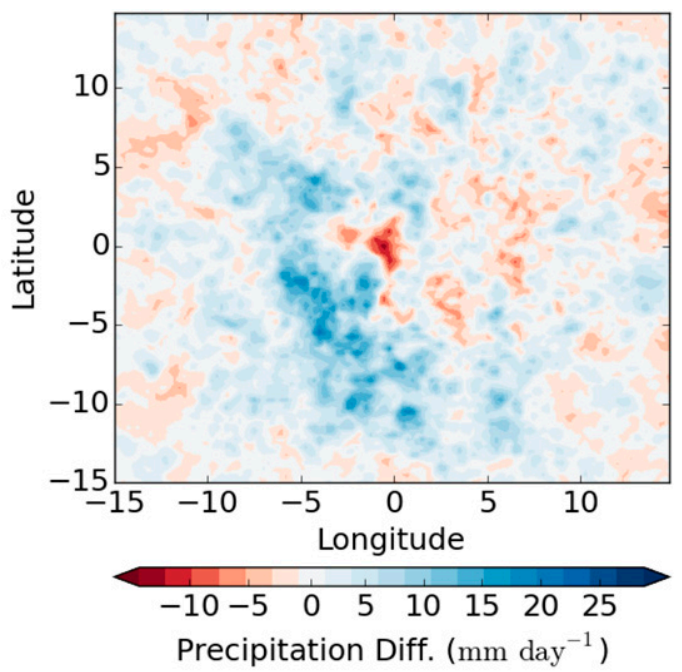

(b) Active-minus-normal

FIG. 22. TRMM rainfall difference composites $\left(\mathrm{mm} \mathrm{day}^{-1}\right)$ for (a) El Niño minus La Niña and (b) active minus normal.

feature is the strong anticyclonic vorticity band located across the Himalayan foothills, seen already in Figs. 5a and $9 \mathrm{c}$. The corresponding region of anomalous positive relative vorticity is strongly correlated with the track density of depressions (see Fig. 1a), with a collocated maximum on the coast of Odisha and West Bengal. There are also several smaller, weaker areas of negative anomalous relative vorticity, notably over Pakistan where many lows eventually dissipate (Krishnamurthy and Ajayamohan 2010). This pattern is in agreement with Godbole (1977). Figure 25a also shows the depression day winds (at $850 \mathrm{hPa}$ ) less the climatology, revealing a structure very similar to that of an activeminus-break composite (Webster et al. 1998), and bearing some resemblance to the equivalent ENSO pattern (Fig. 24b), but it seems to bear no relation to the strength of the monsoon itself (Turner et al. 2005); this demonstrates that certain aspects of large-scale variability (La Niña and active phase) favor the circulation anomaly in which depression days occur. The sign change in zonal wind that occurs at $\sim 20^{\circ} \mathrm{N}$ is greatly assisted by the addition of cyclonic vorticity from the presence of depressions in the north of the Bay of Bengal and over northeast India. The shear imparted on the 850 -hPa easterly by the Himalayas is also visible. For comparison, the difference in $850-\mathrm{hPa}$ winds and relative vorticity between active depression days and nonactive depression days is shown in Fig. 25b. It demonstrates that the active state is an amplification of both the monsoon and the depressionday anomaly, and it therefore corroborates what we saw in Figs. 23g-i, that depressions occurring when the monsoon is active are somewhat more intense (lower central pressure, greater vertical temperature gradient, more moisture) than when it is in a normal or break phase.

\section{Conclusions}

Monsoon depressions are cyclonic tropical lows, averaging 2-5 days in lifetime, that spend much of their time over the Indian subcontinent. They are important as they contribute much rain to the northeast of the Indian peninsula, a region known to be particularly dry in coupled GCMs (Sperber et al. 2013). It is therefore important to quantify their structure, movement, and behavior, so as to evaluate and understand their dynamics. This will in due course enable evaluation and improvement of numerical models, leading to deeper understanding and to more reliable prediction, and thus to improved local community preparedness for flooding and related impacts.

We confirmed the existence of a rainfall maximum in the southwest sector of a rotated northward-propagating depression (Ramanathan and Ramakrishnan 1933; Mooley 1973; Godbole 1977). There are several orders of magnitude between the rainfall maximum of the composite $\left(38.6 \mathrm{~mm} \mathrm{day}^{-1}\right)$ and the maximum individual event $\left(1.6 \mathrm{~m} \mathrm{day}^{-1}\right)$, indicating the diversity and local detail of such extreme events.

Reanalysis data were used on the 106-depression composite to determine horizontal and vertical structure, 

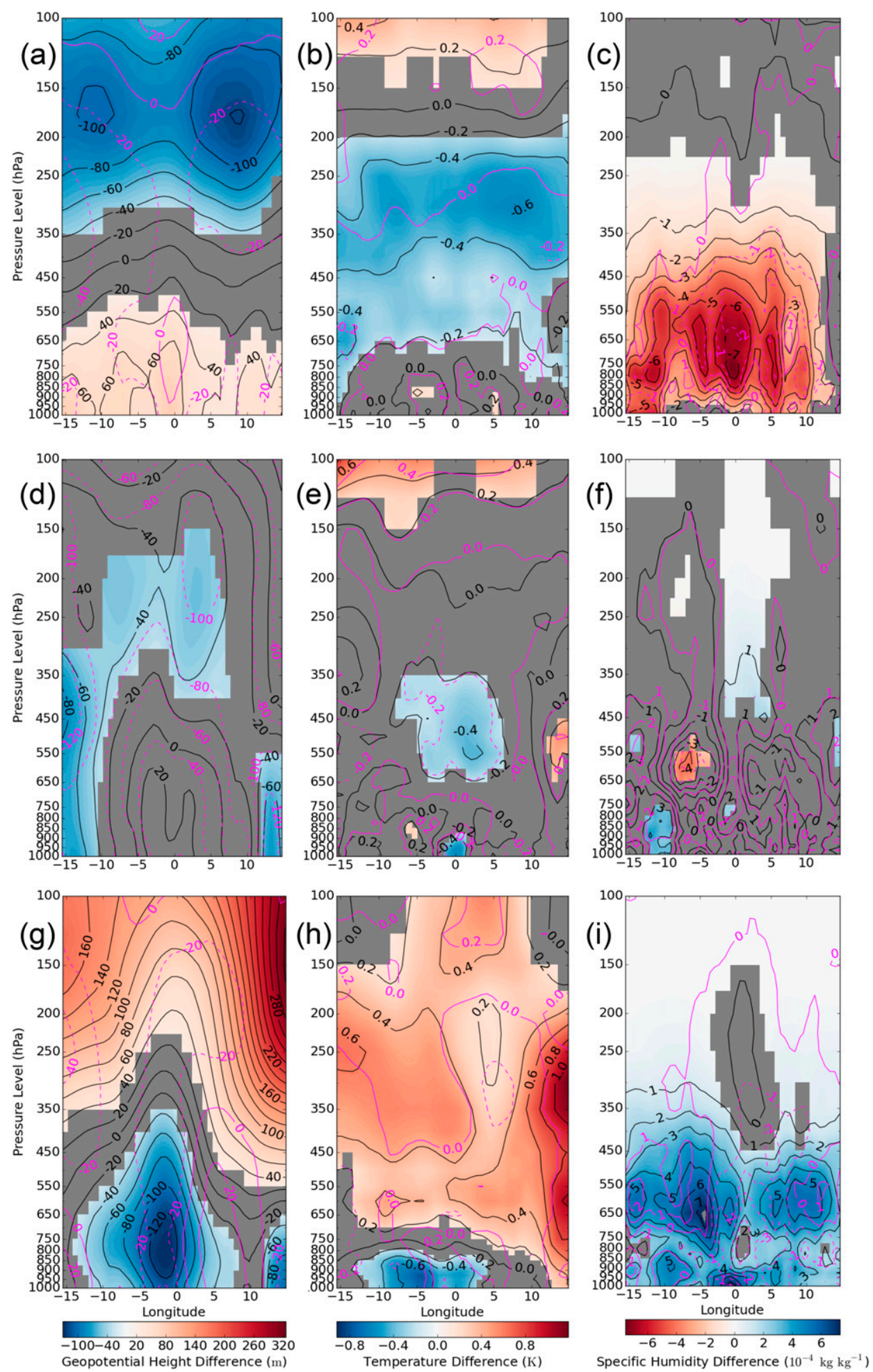

FIG. 23. Vertical structure of the (a)-(c) El-Niño-minus-La-Niña, (d)-(f) IOD positive-minus-negative, and (g)-(i) active-minus-neutral composites for (a),(d),(g) geopotential height (m); (b),(e),(h) temperature (K); and (c),(f),(i) specific humidity $\left(10^{-4} \mathrm{~kg} \mathrm{~kg}^{-1}\right)$. The colors are grayed out in areas where the composite difference does not significantly differ from zero. Magenta line contours represent the same variables with 21-day averages subtracted-this shows the composite difference left once large-scale forcings have been removed. 


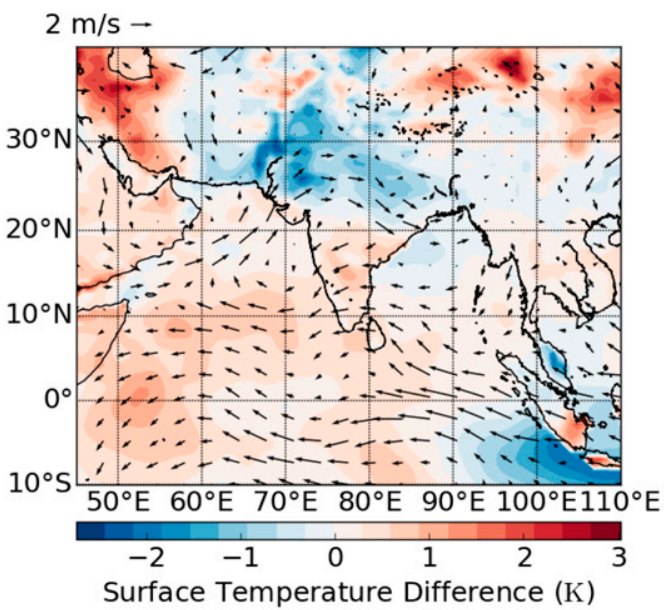

(a) IOD positive-minus-negative depression days

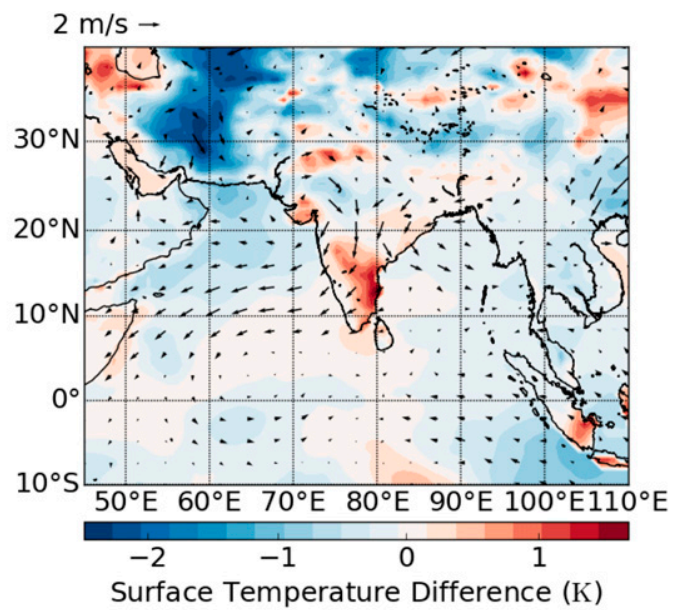

(b) ENSO positive-minus-negative depression days

FIG. 24. Surface temperature (K, colored contours) and wind $\left(\mathrm{m} \mathrm{s}^{-1}\right)$ at $850 \mathrm{hPa}$ for (a) IOD positve-minus-negative and (b) El Niño-minus-La Niña depression days. Note the differing color scales.

showing that many fields have their maximum intensity in the relative southwest sector. The Himalayas were found to have a pronounced anticyclonic effect on the relative east-northeast sector of the depressions, both at the surface and aloft, as confirmed by the relative vorticity field during depression days, which exhibited an intense band of anticyclonicity along the foothills. A schematic diagram of the major results is shown in Fig. 16. We confirmed the warm-over-cold temperature core structure is present in almost all depressions, relating the nearsurface cold core to reduced insolation from increased cloud cover and the warm core aloft to strong latent

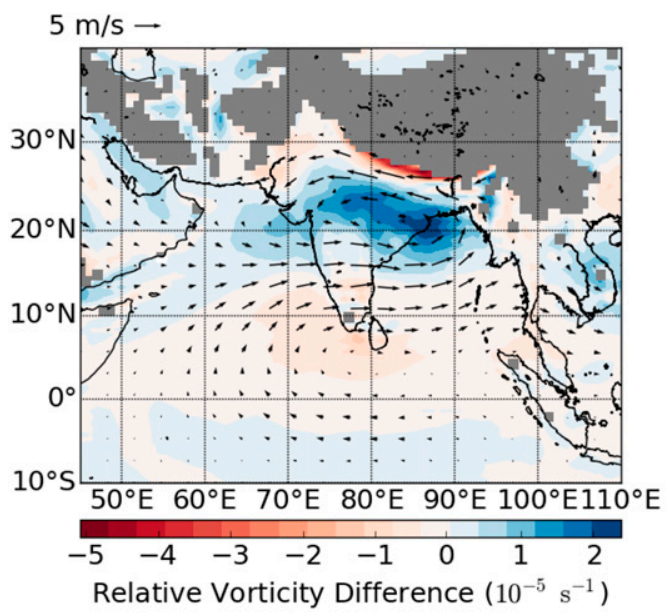

(a) All depression days minus JJAS climatology heating from convective precipitation. We also found a bimodal potential vorticity structure at the center [also recently discovered by Hurley and Boos (2015)], as well as an intensification of the tangential winds on the Himalayan side of the depression.

The slight westward axial tilt observed in, for example, Godbole (1977) was also confirmed in the lower levels in many fields, though some fields also exhibited an eastward axial tilt near the tropopause.

We have shown that depressions can be separated into three separate core types: warm (rare and tropical cyclone-like), neutral (weak temperature anomalies near

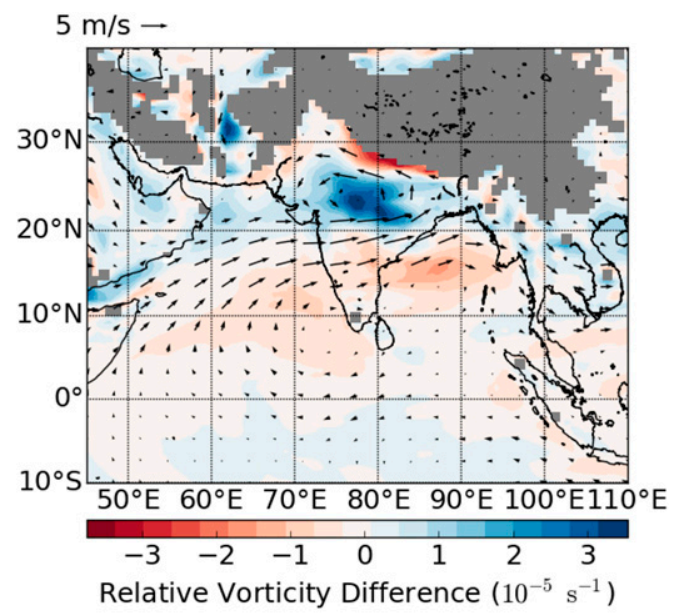

(b) Active-minus-neutral depression days

FIG. 25. Relative vorticity (colored contours, $10^{-5} \mathrm{~s}^{-1}$ ) and wind $\left(\mathrm{m} \mathrm{s}^{-1}\right.$ ) for (a) all depression days as an anomaly to the boreal summer mean and (b) active-minus-neutral depression days. The colored contours are grayed out where the orography rises above the 850 -hPa level. 
the surface, strong warm core aloft, strong temperature anomaly gradient near the tropopause), and cold (much colder at the surface, warm core aloft, most frequent type); we found that cold-core depressions are comparatively more likely to form in El Niño conditions than neutral or La Niña ones and that neutral-core depressions are responsible for greater and more widespread rainfall.

We compared composites of depressions over land and ocean. Most differences were not large given the scatter between depressions, but depressions over land had weaker near-surface winds owing to friction and more anticyclonic vorticity to the relative east owing to the Himalayas. There was no significant difference in potential vorticity between the subsets, although equivalent potential temperature had a more extended maximum (and at a lower altitude) over land owing to differing moisture structures. We also found that the boundary layer height drops over the center of the depression. Latent and sensible surface heat fluxes were also considered as both have minima at the center and strong land-ocean contrasts, latent heat flux being much higher over the ocean.

Depressions during La Niña have moister, more vortical cores than during El Niño. They also have a warmer middle troposphere and slacker vertical geopotential height gradient, and though they yield less intense precipitation at the center, they are associated with higher rainfall rates in the flanks. The influence of the Indian Ocean dipole on monsoon depressions was very slight.

Depressions occurring during active monsoon phases are more intense: greater lower/midtropospheric geopotential height anomaly, greater vertical temperature anomaly gradient, and substantially more moisture throughout. The active-period intensification of the background monsoon conditions strongly resembles an amplification of the depression-day anomaly relative to the monsoon climatology.

Monsoon depressions are colder, wetter, and have more cloud throughout during the local nighttime than the daytime.

Our diagnostics represent a firm basis for assessing monsoon depression representation and behavior in NWP and high-resolution climate models.

Acknowledgments. The lead author receives partial support from the Met Office under the aegis of the NERC CASE studentship scheme, and is also supported by the NERC Grant NE/L501608/1. The Met Office authors are supported by the Joint DECC/Defra Met Office Hadley Centre Climate Programme (GA01101). KH wishes to thank Gill Martin at the Met Office for her insightful comments and the welcome suggestion of a schematic; AGT received partial support from NCAS-Climate and the NERC INCOMPASS project (NE/L01386X/1). We thank the three anonymous reviewers who provided valuable suggestions and critique, most importantly ensuring the statistical robustness of the methods used.

\section{REFERENCES}

Bell, R., K. I. Hodges, P. L. Vidale, J. Strachan, and M. Roberts, 2014: Simulation of the global ENSO-tropical cyclone teleconnection by a high-resolution coupled general circulation model. J. Climate, 27, 6404-6422, doi:10.1175/JCLI-D-13-00559.1.

Boos, W. R., J. V. Hurley, and V. S. Murthy, 2015: Adiabatic westward drift of Indian monsoon depressions. Quart. J. Roy. Meteor. Soc., 141, 1035-1048, doi:10.1002/qj.2454.

Catto, J. L., L. C. Shaffrey, and K. I. Hodges, 2010: Can climate models capture the structure of extratropical cyclones? J. Climate, 23, 1621-1635, doi:10.1175/2009JCLI3318.1.

Cetrone, J., and R. Houze, 2006: Characteristics of tropical convection over the ocean near Kwajalein. Mon. Wea. Rev., 134, 834-853, doi:10.1175/MWR3075.1.

Cohen, N. Y., and W. R. Boos, 2014: Has the number of Indian summer monsoon depressions decreased over the last 30 years? Geophys. Res. Lett., 41, 7846-7853, doi:10.1002/2014GL061895.

Dacre, H. F., M. K. Hawcroft, M. A. Stringer, and K. I. Hodges, 2012: An extratropical cyclone atlas: A tool for illustrating cyclone structure and evolution characteristics. Bull. Amer. Meteor. Soc., 93, 1497-1502, doi:10.1175/BAMS-D-11-00164.1.

Dee, D. P., and Coauthors, 2011: The ERA-Interim reanalysis: Configuration and performance of the data assimilation system. Quart. J. Roy. Meteor. Soc., 137, 553-597, doi:10.1002/qj.828.

DeMaria, M., 1996: The effect of vertical shear on tropical cyclone intensity change. J. Atmos. Sci., 53, 2076-2088, doi:10.1175/ 1520-0469(1996)053<2076:TEOVSO > 2.0.CO;2.

Desai, B. N., 1951: On the development and structure of monsoon depressions in India. Mem. Indian Meteor. Dept., 28, 217-228.

Dhar, O. N., and P. R. Rakhecha, 1976: Does the absence of cyclonic disturbances cause deficient rainfall in north Indian subdivisions during monsoon months? Proc. Indian Natl. Sci. Acad., 42, 81-89.

Ding, Y.-H., 1981: A case study of formation and structure of a depression over the Arabian Sea. Chin. J. Atmos. Sci., 5, 267-280.

- X. Q. Fu, and B. Y. Zhang, 1984: A study of the structure of a monsoon depression over the Bay of Bengal during the summer MONEX. Adv. Atmos. Sci., 1, 62-75, doi:10.1007/BF03187617.

Efron, B., 1979: Bootstrap methods: Another look at the jackknife. Ann. Stat., 7, 1-26, doi:10.1214/aos/1176344552.

Felton, C. S., B. Subrahmanyam, and V. S. N. Murty, 2013: ENSOmodulated cyclogenesis over the Bay of Bengal. J. Climate, 26, 9806-9818, doi:10.1175/JCLI-D-13-00134.1.

Godbole, R., 1977: The composite structure of the monsoon depression. Tellus, 29, 25-40, doi:10.1111/j.2153-3490.1977. tb00706.x.

Hawkins, H., and D. Rubsam, 1968: Hurricane Hilda, 1964. II. Structure and budgets of the hurricane on October 1, 1964. Mon. Wea. Rev., 96, 617-636, doi:10.1175/1520-0493(1968)096<0617: $\mathrm{HH}>2.0 . \mathrm{CO} ; 2$.

— hurricane-Inez 1966. Mon. Wea. Rev., 104, 418-442, doi:10.1175/ 1520-0493(1976)104<0418:TSOASI >2.0.CO;2.

Hess, M., P. Koepke, and I. Schult, 1998: Optical properties of aerosols and clouds. Bull. Amer. Meteor. Soc., 79, 831-844, doi:10.1175/1520-0477(1998)079<0831:OPOAAC >2.0.CO;2. 
Houze, R. A., Jr., 2010: Review: Clouds in tropical cyclones. Mon. Wea. Rev., 138, 293-344, doi:10.1175/2009MWR2989.1.

Huffman, G. J., and Coauthors, 2007: The TRMM Multisatellite Precipitation Analysis (TMPA): Quasi-global, multiyear, combined-sensor precipitation estimates at fine scales. J. Hydrometeor., 8, 38-55, doi:10.1175/JHM560.1.

—, R. F. Adler, D. T. Bolvin, and E. J. Nelkin, 2010: The TRMM multi-satellite precipitation analysis (TMPA). Satellite Rainfall Applications for Surface Hydrology, M. Gebremichael and F. Hossain, Eds., Springer, 3-22.

Hurley, J. V., and W. R. Boos, 2015: A global climatology of monsoon low pressure system. Quart. J. Roy. Meteor. Soc., 141, 1049-1064, doi:10.1002/qj.2447.

Kikuchi, K., and B. Wang, 2010: Formation of tropical cyclones in the Northern Indian Ocean associated with two types of tropical intraseasonal oscillation modes. J. Meteor. Soc. Japan, 88, 475-496, doi:10.2151/jmsj.2010-313.

Kozu, T., and Coauthors, 2001: Development of precipitation radar onboard the Tropical Rainfall Measuring Mission (TRMM) satellite. IEEE Trans. Geosci. Remote Sens., 39, 102-116, doi:10.1109/36.898669.

Krishnamurthy, V., and J. Shukla, 2007: Intraseasonal and seasonally persisting patterns of Indian monsoon rainfall. J. Climate, 20, 3-20, doi:10.1175/JCLI3981.1.

—_ and R. S. Ajayamohan, 2010: Composite structure of monsoon low pressure systems and its relation to Indian rainfall. J. Climate, 23, 4285-4305, doi:10.1175/2010JCLI2953.1.

Krishnan, R., D. Ayantika, V. Kumar, and S. Pokhrel, 2011: The long-lived monsoon depressions of 2006 and their linkage with the Indian Ocean Dipole. Int. J. Climatol., 31, 1334-1352, doi:10.1002/joc. 2156.

Kummerow, C., W. Barnes, T. Kozu, J. Shiue, and J. Simpson, 1998: The Tropical Rainfall Measuring Mission (TRMM) sensor package. J. Atmos. Oceanic Technol., 15, 809-817, doi:10.1175/ 1520-0426(1998)015<0809:TTRMMT>2.0.CO;2.

La Seur, N., and H. Hawkins, 1963: An analysis of Hurricane Cleo (1958) based on data from research reconnaissance aircraft. Mon. Wea. Rev., 91, 694-709, doi:10.1175/1520-0493(1963)091<0694: $\mathrm{AAOHCB}>2.3 . \mathrm{CO} ; 2$.

LeMone, M., E. Zipser, and S. Trier, 1998: The role of environmental shear and thermodynamic conditions in determining the structure and evolution of mesoscale convective systems during TOGA COARE. J. Atmos. Sci., 55, 3493-3518, doi:10.1175/1520-0469(1998)055<3493:TROESA > 2.0.CO;2.

Liu, Z., D. Ostrenga, W. Teng, and S. Kempler, 2012: Tropical Rainfall Measuring Mission (TRMM) precipitation data and services for research and applications. Bull. Amer. Meteor. Soc., 93, 1317-1325, doi:10.1175/BAMS-D-11-00152.1.

Mooley, D. A., 1973: Some aspects of Indian monsoon depressions and the associated rainfall. Mon. Wea. Rev., 101, 271-280, doi:10.1175/1520-0493(1973)101<0271:SAOIMD>2.3.CO;2.

Mull, S., and Y. P. Rao, 1949: Indian tropical storms and zones of heavy rainfall. Indian J. Phys., 23, 371-377.

Nair, S., G. Srinivasan, and R. Nemani, 2009: Evaluation of multisatellite TRMM derived rainfall estimates over a western state of India. J. Meteor. Soc. Japan, 87, 927-939, doi:10.2151/jmsj.87.927.

Pai, D. S., L. Sridhar, M. Rajeevan, O. P. Sreejith, N. S. Satbhai, and B. Mukhopadhyay, 2014: Development of a new high spatial resolution $\left(0.25^{\circ} \times 0.25^{\circ}\right)$ long period (1901-2010) daily gridded rainfall data set over India and its comparison with existing data sets over the region. Mausam (New Delhi), 65, 1-18.

Petterssen, S., 1956: Motion and Motion Systems. Vol. 1, Weather Analysis and Forecasting, McGraw-Hill, 428 pp.
Prajeesh, A. G., K. Ashok, and D. V. Bhaskar Rao, 2013: Falling monsoon depression frequency: A Gray-Sikka conditions perspective. Sci. Rep., 3, 1-8, doi:10.1038/srep02989.

Prakash, S., and R. Gairola, 2014: Validation of TRMM-3B42 precipitation product over the tropical Indian Ocean using rain gauge data from the RAMA buoy array. Theor. Appl. Climatol., 115, 451-460, doi:10.1007/s00704-013-0903-3.

Prasad, K., S. R. Kalsi, and R. K. Datta, 1990: On some aspects of wind and cloud structure of monsoon depressions. Mausam (New Delhi), 41, 365-370.

Raghavan, K., 1967: Influence of tropical storms on monsoon rainfall in India. Weather, 22, 250-256, doi:10.1002/ j.1477-8696.1967.tb02929.x.

Ramage, C. S., 1959: Hurricane development. J. Meteor., 16, $227-$ 237, doi:10.1175/1520-0469(1959)016<0227:HD>2.0.CO;2.

Ramanathan, K. R., and K. P. Ramakrishnan, 1933: The Indian southwest monsoon and the structure of depressions associated with it. Mem. Indian Meteor. Dept., 26, 13-36.

Rasmusson, E. M., and T. H. Carpenter, 1983: The relationship between eastern equatorial Pacific sea surface temperatures and rainfall over India and Sri Lanka. Mon. Wea. Rev., 111, 517-528, doi:10.1175/1520-0493(1983)111<0517:TRBEEP>2.0.CO;2.

Ropelewski, C. F., and M. S. Halpert, 1987: Global and regional scale precipitation patterns associated with the El Niño/ Southern Oscillation. Mon. Wea. Rev., 115, 1606-1626, doi:10.1175/1520-0493(1987)115<1606:GARSPP>2.0.CO;2.

Rosenfeld, D., and I. M. Lensky, 1998: Satellite-based insights into precipitation formation processes in continental and maritime convective clouds. Bull. Amer. Meteor. Soc., 79, 2457-2476, doi:10.1175/1520-0477(1998)079<2457:SBIIPF>2.0.CO;2.

Roy, S. C., and A. K. Roy, 1930: Structure and movement of cyclones in the Indian seas. Beitr. Phys. Atmos., 26, 224-234.

Saha, K., F. Sanders, and J. Shukla, 1981: Westward propagating predecessors of monsoon depressions. Mon. Wea. Rev., 109, 330-343, doi:10.1175/1520-0493(1981)109<0330: WPPOMD $>2.0 . \mathrm{CO} ; 2$.

Saji, N., B. Goswami, P. Vinayachandran, and T. Yamagata, 1999: A dipole mode in the tropical Indian ocean. Nature, 401, 360-363.

Sarker, R. P., and A. Choudhary, 1988: A diagnostic study of monsoon depressions. Mausam (New Delhi), 39, 9-18.

Sikka, D. R., 1977: Some aspects of the life history, structure and movement of monsoon depressions. Pure Appl. Geophys., 115, 1501-1529, doi:10.1007/BF00874421.

, 2006: A study on the monsoon low pressure systems over the Indian region and their relationship with drought and excess monsoon seasonal rainfall. Center for Ocean-LandAtmosphere Studies Tech. Rep., 61 pp.

— , and D. K. Paul, 1975: A diagnostic study on the structure of monsoon depressions. Geophysical Fluid Dynamics Workshop: Monsoon Meteorology, Bangalore, India, 136-182.

Slingo, J. M., 1987: The development and verification of a cloud prediction scheme for the ECMWF. Quart. J. Roy. Meteor. Soc., 113, 899-927, doi:10.1002/qj.49711347710.

Sperber, K. R., H. Annamalai, I.-S. Kang, A. Kitoh, A. Moise, A. Turner, B. Wang, and T. Zhou, 2013: The Asian summer monsoon: An intercomparison of CMIP5 vs. CMIP3 simulations of the late 20th century. Climate Dyn., 41, 2711-2744, doi:10.1007/s00382-012-1607-6.

Stano, G., T. N. Krishnamurti, T. S. V. Vijaya Kumar, and A. Chakraborty, 2002: Hydrometeor structure of a composite monsoon depression using the TRMM radar. Tellus, 54A, 370-381, doi:10.1034/j.1600-0870.2002.01330.x. 
Stern, D. P., and D. S. Nolan, 2012: On the height of the warm core in tropical cyclones. J. Atmos. Sci., 69, 1657-1680, doi:10.1175/JAS-D-11-010.1.

Sundqvist, H., E. Berge, and J. E. Kristjansson, 1989: Condensation and cloud studies with a mesoscale numerical weather prediction model. Mon. Wea. Rev., 117, 1641-1657, doi:10.1175/ 1520-0493(1989)117<1641:CACPSW >2.0.CO;2.

Turner, A. G., P. M. Inness, and J. M. Slingo, 2005: The role of the basic state in the ENSO-monsoon relationship and implications for predictability. Quart. J. Roy. Meteor. Soc., 131, 781804, doi:10.1256/qj.04.70.
Webster, P. J., and S. Yang, 1992: Monsoon and ENSO: Selectively interactive systems. Quart. J. Roy. Meteor. Soc., 118, 877-926, doi:10.1002/qj.49711850705.

—, V. O. Magaña, T. N. Palmer, J. Shukla, R. A. Tomas, M. Yanai, and T. Yasunari, 1998: Monsoons: Processes, predictability, and the prospects for prediction. J. Geophys. Res., 103, 14 451-14 510, doi:10.1029/ 97JC02719.

Yoon, J.-H., and T.-C. Chen, 2005: Water vapor budget of the Indian monsoon depression. Tellus, 57A, 770-782, doi:10.1111/ j.1600-0870.2005.00145.x. 